\title{
Anti-inflammatory Action of Statins in Cardiovascular Disease: the Role of Inflammasome and Toll-Like Receptor Pathways
}

\author{
Khadijeh Koushki ${ }^{1}$ - Sanaz Keshavarz Shahbaz ${ }^{1}$. Kazem Mashayekhi ${ }^{1} \cdot$ Mahvash Sadeghi $^{1} \cdot$ Zeinab Deris Zayeri $^{2}$. \\ Mahdieh Yousefi Taba ${ }^{3}$. Maciej Banach ${ }^{4,5} \cdot$ Khalid Al-Rasadi $^{6,7} \cdot$ Thomas P. Johnston $^{8} \cdot$ Amirhossein Sahebkar $^{9,10,11}$
}

Published online: 6 May 2020

(C) The Author(s) 2020

\begin{abstract}
Atherosclerosis is one type of cardiovascular disease (CVD) in which activation of the NLRP3 inflammasome and toll-like receptor (TLR) pathways is implicated. One of the most effective treatments for atherosclerosis is the use of statin medications. Recent studies have indicated that statins, in addition to their lipid-lowering effects, exert inhibitory and/or stimulatory effects on the NLRP3 inflammasome and TLRs. Some of the statins lead to activation of the inflammasome and subsequently cause secretion of IL-1 $\beta$ and IL-18. Thus, these actions may further aggravate the disease. On the other hand, some statins cause inhibition of the inflammasome or TLRs and along with lipid-lowering, help to improve the disease by reducing inflammation. In this article, we discuss these contradictory studies and the mechanisms of action of statins on the NLRP3 inflammasome and TLR pathways. The dose-dependent effects of statins on the NLRP3 complex are related to their chemistry, pharmacokinetic properties, and danger signals. Lipophilic statins have more pleiotropic effects on the NLRP3 complex in comparison to hydrophilic statins. Statins can suppress TLR4/MyD88/NF-KB signaling and cause an immune response shift to an anti-inflammatory response. Furthermore, statins inhibit the NF-KB pathway by decreasing the expression of TLRs 2 and 4. Statins are costeffective drugs, which should have a continued future in the treatment of atherosclerosis due to both their immune-modulating and lipid-lowering effects.
\end{abstract}

Keywords Statins $\cdot$ NLRP3 $\cdot$ Inflammasome $\cdot$ TLR4 $\cdot$ TLR2 $\cdot$ Cardiovascular disease $\cdot$ Atherosclerosis

\section{Introduction}

Chronic inflammation has been recognized as an important factor in the development of inflammatory diseases such as

\section{Highlights}

- Atherosclerosis can be triggered through the NLRP3 inflammasome and TLR pathway.

- Cholesterol crystals (CCs) and oxidized LDL (ox-LDL) act as NLRP3 inflammasome and TLR danger signals in atherosclerosis.

- Statins are lipid-lowering drugs with anti-inflammatory properties, and it appears that the anti-inflammatory effects of statins on the NLRP3 complex are related to their chemistry, pharmacokinetic properties, and 'danger signals' such as CCs and/or ox-LDL.

- Lipophilic statins have a greater number of pleiotropic effects on the NLRP3 complex in comparison to hydrophilic statins.

- Statins inhibit NF-KB by decreasing the expression of TLRs 2 and 4, reducing the levels of LOX-1 receptors, exerting positive effects on inhibitory miRNAs, reducing protein adaptors, and stabilizing inhibitors of NF-кB.

Amirhossein Sahebkar

sahebkara@mums.ac.ir; amir_saheb2000@yahoo.com

Extended author information available on the last page of the article atherosclerosis, which leads to functional and structural abnormalities of vascular walls. Atherosclerosis develops as a result of genetic and environmental interactions that cause inflammation and ultimately leads to endothelial cell dysfunction and thrombotic blockage. Elevated cholesterol and LDLcholesterol (LDL-C) levels are the main risk factors that associated with the formation of atherosclerotic plaques and the development of atherosclerosis [1], which is characterized by lipid deposition, leukocyte infiltration, and smooth muscle cell proliferation in the vascular walls $[2,3]$.

Innate immunity is the first line of defense in the human body, which occurs in response to recognized antigens via receptors or so-called pattern-recognition receptors (PRRs). These receptors are found on innate immune cells such as macrophages, neutrophils, and other inflammatory cells [4]. The PRRs are divided into five groups: toll-like receptors (TLRs), NOD-like receptors (NLRs), RIG-I-like receptors (RLRs), C-type lectin receptors (CTLs), and AIM2-like receptors (ALRs). Some of them are located on the membrane of the cell (e.g., TLRs and CTLs), while other families are cytoplasmic receptors and expressed in the cytoplasmic space 
(e.g., NLRs and RLRs) [5]. The PRR-related signaling pathway has recently been identified as the bridge between the innate immune system and inflammatory diseases such as atherosclerosis and autoimmunity, especially NLRs and TLRs [6-8]. NOD-like receptors (NLRs), especially NLRP3, are the well-known receptor that detects the endogenous danger signal created by the presence of cholesterol crystals (CCs), which leads to activation of the inflammasome complex that activates caspase-1. Subsequently, active caspase-1 leads to proteolytic cleavage of pro-inflammatory cytokines such as pro-IL-1 $\beta$ and pro-IL-18 into their mature and active forms [9], which are the most important cytokines involved in the progression of atherosclerosis. The presence of CCs and elevated LDL are the main stimulators involved in the pathogenesis of atherosclerosis, which leads to NLRP3 inflammasome activation [10]. Moreover, the TLRs can identify endogenous ligands such as oxidized LDL (ox-LDL), heat shock proteins (HSP), high mobility group box 1 protein (HMGB1), fibrinogen, beta-defensin, and heparan sulfate. These endogenous proteins are often released in response to stress or tissue damage at sites of chronic inflammation [8]. Therefore, TLRs may be involved in pathological inflammatory diseases such as atherosclerosis.

Several anti-inflammatory drugs have been tested for their potential of reducing atherosclerosis risk. Statins are a good example of anti-inflammatory drugs that reduce the effects of inflammatory cytokines. Recent studies have shown that statins, in addition to their lipid-lowering effects, exert inhibitory or stimulatory effects on the NLRP3 inflammasome and TLRs. Some of the statins mediate an activation of the inflammasome, which subsequently leads to the secretion of IL-1 $\beta$ and IL-18. Thus, this action may result in further aggravation of the CVD. On the other hand, some statins cause inhibition of the inflammasome or TLRs, which leads to a reduction in inflammation. Together with their lipidlowering effects, this outcome results in an improvement of the disease. In this review, we focus on these conflicting studies and the mechanisms of action of statins on the NLRP3 inflammasome and TLRs pathways.

\section{Inflammatory Responses and Atherosclerosis}

\section{Start of Inflammation}

Atherosclerosis is a complex inflammatory process characterized by fat deposition, leukocyte infiltration, and smooth muscle cell proliferation in the vascular walls $[2,3]$. Since the atherosclerotic process occurs predominantly in the absence of microbial infection, it is considered a 'sterile' inflammation [11]. Chronic inflammation of the vessel walls is the main stimulator that is involved in the pathogenesis of atherosclerosis [10]. Additionally, macrophages are the most dominant cells involved in atherosclerosis [12]. For the first time, Ross R. et al. described a key event in the formation of atherosclerotic plaque, which included the role of macrophages in transendothelial migration, the proliferation of smooth muscle cells, the involvement of lymphocytes, and their migration to the intima [13]. Lipoproteins present in the vascular walls cause cholesterol crystallization, which is an aggravating factor in atherosclerosis and causes cellular damage and apoptosis. The CCs are hallmarks of advanced atherosclerotic plaques and indicate the instability and vulnerability of plaques to rupture [14].

\section{Progression of Inflammation}

The accumulation of LDLs in the sub-endothelial environment is an essential event for the onset of atherosclerosis. Endothelial dysfunction occurs when endothelial cells are damaged or subjected to conditions of metabolic stress. One of the characteristics of endothelial dysfunction is the increased production of reactive oxygen species (ROS) [15]. ROS contribute to the oxidation of accumulated LDL and ultimately produce ox-LDL. Oxidized LDL exerts proatherogenic effects and it can induce the expansion of inflammatory macrophage phenotypes and lead to the formation of foam cells and endothelial dysfunction in the subendothelial site. Another way of generating these atherogenic species is via inflammatory cells, which by producing phospholipase A2 (PLA2), particularly lipoproteinassociated PLA2 and type II secretory PLA2, leads to additional oxidation of the phosphides in LDL particles and eventually the creation of atherogenic species [16]. Ultimately, ox-LDL activates endothelial cells, which subsequently produce adherent molecules such as vascular cell adhesion protein-1 (VCAM-1), intercellular adhesion molecule-1 (ICAM-1), and selectins, which are accompanied by complement factors and chemoattractant mediators such as IL-8 and monocyte chemoattractant protein-1 (MCP-1). Consequently, these molecules mediate the translocation of mononuclear cells to the intima. Also, macrophages and neutrophils participate in atherothrombosis. In some patients, atherothrombosis occurs following the rupture of an atheroma, which may be triggered through neutrophil extracellular traps (NETs). The NETs are networks of extracellular fibers, primarily composed of DNA from neutrophils, chromatin, serine proteases, and nuclear proteins, which bind pathogens. Plaque rupture triggers fibrin deposition and platelet aggregation at the initial site to entrap circulating red blood cells (RBCs). The interaction of thrombin-activated platelets with polymorphonuclear leukocytes (PMNs) at the site of plaque rupture during acute MI results in local formation of NETs and causes atherothrombosis. 


\section{Stability of Inflammation}

As discussed, intrinsic immune cells have receptors that are activated following the identification of pathogen-associated molecular patterns (PAMPs) and damage-associated molecular pattern molecules (DAMPs). Oxidized-LDL, as a DAMP molecule, is linked to CD36 and is phagocytosed by macrophages. However, CD36 is resistant to macrophage lysosomal enzymes, which leads to the accumulation of ox-LDL in macrophages and the formation of foam cells. This process ultimately produces a wide range of pro-inflammatory cytokines (e.g., IL-1, IL-8, IL-31, L-18, and TNF- $\alpha$ ), as well as the expression of receptors (e.g., CD40L and CD40) [17]. Data from both experimental and epidemiological studies confirm a significant role of IL- 6 and TNF- $\alpha$, and especially IL- $1 \beta$ cytokines, in the development of atherosclerosis. [18].

Cholesterol crystals (CCs) and ox-LDL play a primary role in plaque formation and are associated with inflammasome activation. The inflammasome was discovered in 2002 and is composed of a complex of proteins that are involved in the maturation and secretion of IL-1 $\beta$ and IL-18 [9]. Recent studies suggest that the inflammasome plays a central role in the pathogenesis of cardiovascular diseases such as atherosclerosis, hypertension, and vascular inflammation [19]. It has also been shown that ox-LDL enhances the expression of TLRs. This is probably due to ox-LDL acting as a ligand for TLRs and subsequent signaling through the NF-KB transcription factor, which eventually leads to the synthesis of inflammatory cytokines and chemokines [20]. As shown in Fig. 1, the accumulation of CCs and the activation of PLA2 are the beginning of the inflammatory process and the migration of immune cells into the intima. This process eventually leads to activation of the inflammasome, TLRs, and the subsequent production of pro-inflammatory cytokines such as IL$1 \beta$ and IL-18.

\section{The Role of IL-1 $\beta$ in Atherosclerosis Development}

Cytokines are signaling molecules and regulatory agents of the immune system, which act as the main mediators of immune-modulation and inflammation. These molecules include diverse groups that clustered into several families such as the chemokines, interleukins (ILs), interferons (IFNs), tumor necrosis factors (TNFs), transforming growth factors (TGFs), and colony-stimulating factors (CSFs). These cytokines are categorized as having anti- or pro-atherogenic properties, which are expressed at atherogenic sites [21-23]. All immune and non-immune cells that may potentially play a role in the pathogenesis of CVD produce and react to these cytokines (Fig. 1).
The IL-1 family includes seven pro-inflammatory cytokines (e.g., IL-1 $\alpha$, IL-1 $\beta$, IL-18, IL-33, IL-36 $\alpha$, IL-36 $\beta$, and

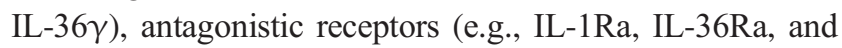
IL-38), and an anti-inflammatory cytokine (e.g., IL-37), which have central roles in immune-based inflammation [24]. The family of IL-1 molecules is secreted from various cells such as macrophages, endothelial cells, and pancreatic islet cells. These inflammatory and intrinsic immune defense properties are referred to as 'inherent immunity' and enhance the response to acquired immunogenic antigens [25, 26]. Most immune cells express IL-1 family members or receptors, so most immune cells are affected by signaling mediated through the IL-1 family, such as the members IL- $1 \alpha$, IL- $1 \beta$, and IL-18. Furthermore, this family of molecules plays an important role in the differentiation and function of lymphoid cells in acquired and inherent immune responses [24]. Inflammatory cytokines, particularly IL-1 $\beta$ and IL-18, play varying roles in the development of atherosclerosis [27]. IL- $1 \alpha$ and IL-1 $\beta$ are the most well-known members of the IL- 1 family and are referred to as precursors. Although the IL- $1 \alpha$ precursor is biologically active, the IL-1 $\beta$ precursor requires proteolytic cleavage to the active form. Its activation is controlled and regulated at different levels [28]. Production and synthesis of IL- $1 \beta$ is monitored and controlled by complex mechanisms. Two signals are required for this process. Initially, the stimulation of pathogen recognition receptors (PRRs) by proinflammatory stimuli eventually leads to NF-KB induction. The second signal involves activating caspase- 1 so that proIL-1 $\beta$ can be converted into the biologically-active form [29]. Caspase- 1 is the main processor of IL-1 $\beta$ and is abundantly found in hematopoietic cells [9]. In addition to the caspase-1 pathway, other enzymes such as protease 3 (pr3) in neutrophils [30] and other proteases such as neutrophil elastase (NE) [31], matrix metallopeptidase-9 (MMP-9) [32], and cathepsin $\mathrm{G}$, as well as kinase in mast cells [33], are all involved in the extracellular processing of IL- $1 \beta$.

Many in vitro and in vivo studies have shown the role of IL-1 in atherosclerosis and CVD and have provided strong evidence that IL- $1 \beta$ is a potent pro-atherogenic factor $[34$, 35]. The increased levels of IL- $1 \beta$ observed in atherosclerotic lesions located in coronary arteries are associated with the severity of the disease [36]. The role of this cytokine has been widely investigated and documented for all stages of atherosclerosis development [37]. This pro-inflammatory mediator is involved in endothelial dysfunction and affects the arterial wall and endothelial cells, as well as increases the expression of adhesion molecules. Increased expression of adhesion molecules leads to the migration of immune cells to the atherogenic site; specifically, macrophages enter the intimal space during the initial phase. Macrophages, in turn, induce the secretion of inflammatory molecules such as chemokines and acute phase reactants such as IL-6, IL-8, MCP-1, and plasminogen activator inhibitor-1 (PAI-1) from endothelial and 
a
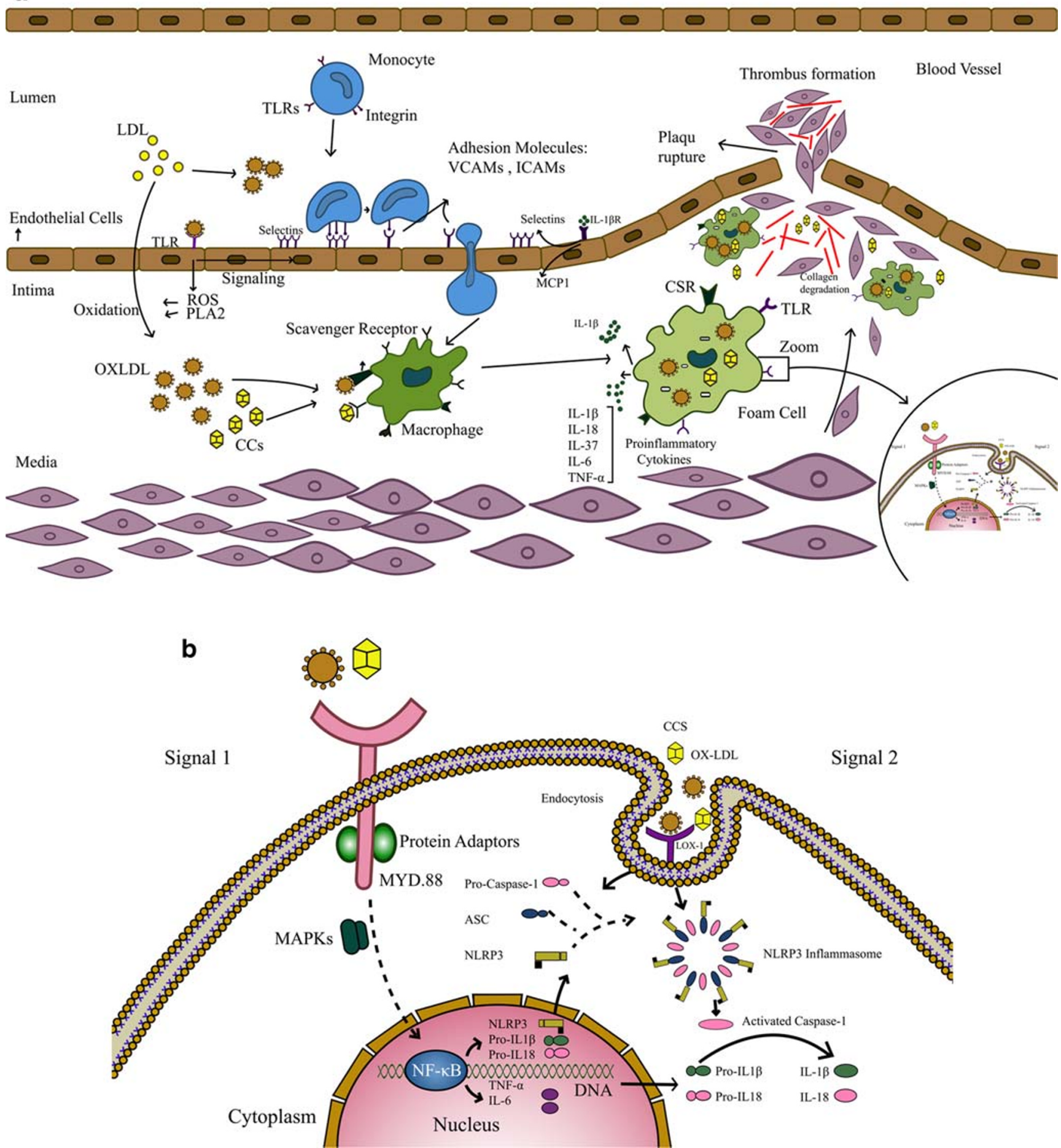

smooth muscle cells. These events increase the inflammatory macrophage phenotype, which exerts effects on cardiac muscle cells to promote their proliferation [19].

It has been shown that in IL-1 knockout mouse models of atherosclerosis, there is a decrease in foam cell formation and lesion size [38]. Moreover, IL-1 plays a significant role in the expression and activation of proteases such as MMPs, which ultimately lead to plaque rupture and obstructive thrombosis
[39]. Thus, IL-1 plays a critical role in the onset, progression, development, and instability of plaque and clot formation in atherosclerosis. The expressions of IL- $1 \alpha$ and IL- $1 \beta$ have also been reported during the development of atherosclerotic plaque. In fact, complex plaques have higher expressions of this cytokine in comparison to simple plaques, while healthy coronary arteries have the lowest expression of this cytokine [40]. Clinical studies have shown that the plasma levels of IL- 
Fig. 1 The roles of NLRPs and TLRs pathways in atherosclerosis pathophysiology. a At first, cholesterol and LDL deposit on vascular walls. Endothelial cells are stimulated through TLRs and resulted in ROS and PLA2 production. The ROS and PLA2 enzymes affected on accumulated LDL and cholesterol and produced ox-LDL and CCs. The ox-LDL and CCs ultimately, active endothelial cells and produce adherent molecules such as VCAM-1, which they evoke the monocular cells to the vascular wall. The ox-LDL and CCs as DAMPs are linked to NLRs and TLRs on phagocytized but they are resistant to macrophage lysosomal enzymes thus leads to the accumulation in macrophages and formats the foam cells which produce the wide range of pro-inflammatory cytokines. The IL-1 $\beta$ is one of the most important cytokines in atherosclerosis plaque and it has many roles such as increases the expression of adhesion molecules, which causes immune cells migration to the atherogenic site, smooth muscle cells proliferation, and MMPs activation, which lead to plaque rupture and obstructive thrombosis. b The stability of inflammation in atherosclerosis is required two signals; the initial signal is triggered via PRR receptors such as TLR, which activates NF-KB pathway that resulting in transcription of NLRP 3 and pro-inflammatory cytokines such as pro-IL$1 \beta$, and the second signal is oligomerisation of activated NLRP3, and then call caspase-1 via Asc adaptor and eventually the formation of the inflammasome, which leads to proteolytic cleavage and activates proinflammatory cytokines such as pro-IL-1 $\beta$ and pro-IL-18 (abbreviations: CSR: cellular stress response is a macrophage scavenger receptor. IL-1 $\beta R$ : interleukin-1 $\beta$ receptor. LDL: low-density lipoprotein. OXLDL: oxidized LDL. NLRs: NOD-like receptor. NLRPs: Is an NLRs. TLR: toll-like receptor. VCAMs: vascular cell adhesion protein. ICAMs: intercellular adhesion molecule. MCP1: monocyte chemoattractant protein-1. ROS: reactive oxygen species. PLA2: phospholipases A2. CCs: cholesterol crystals. DAMPs: damage-associated molecular patterns. MMPs: matrix metalloproteinases. PRR: pattern recognition receptors. NF-кB: nuclear factor kappa-light-chain-enhancer of activated B cells. Asc: apoptosis-associated speck-like protein containing a CARD. MAPKs: mitogen-activated protein kinase. TNF$\alpha$ : tumor necrosis factor- $\alpha$. IL: interleukin. Lox-1: lectin-type oxidized LDL receptor-1. MyD-88: myeloid differentiation primary response-88)

$1 \beta$ are higher in CAD patients in comparison to non-CAD patients, and this finding is associated with an increased incidence of cardiovascular events in patients who have atherosclerotic risk factors [41-43]. In addition, various animal models have demonstrated the pro-atherogenic properties of the IL-1 $\beta$ cytokine. In this regard, silencing IL-1 $\beta$ in apoEdeficient mice $\left(\mathrm{ApoE}^{-/-}\right)$that are susceptible to atherosclerosis has revealed a reduction in the rate and extent of coronary atherosclerosis [35]. Experimental studies on atherosclerosissusceptible animals have shown that either genetic deletion, or pharmacological inhibition of IL-1 signals, reduces both the formation and rate of progression of atherosclerotic plaques. In contrast, either an increase in active IL-1 that is formed after the injection of exogenous IL-1 $\beta$, or a reduction in IL-1Ra, can lead to plaque enlargement and further the progression of atherosclerosis [44].

Based on these findings, the Canakinumab AntiInflammatory Thrombosis Outcomes Study (CANTOS trial) designed to show the importance of the IL-1 pathway in atherosclerosis. This study investigated the role of IL-1 in inflammation during atherosclerosis and the protective potential of anti-inflammatory drugs during CVD development. In this trial, canakinumab (a monoclonal antibody against IL-1 $\beta$ ) was examined for its potential in reducing the number and frequency of secondary myocardial infarction (MI) events in cardiac patients. The results of this trial demonstrated that canakinumab, by decreasing inflammation, resulted in a reduced risk of cardiovascular events without affecting blood cholesterol levels. Therefore, it was the first large-scale randomized study that confirmed the hypothesis that IL- $1 \beta$ was pro-atherogenic and proved that inhibition of inflammation has a beneficial effect on the progression of CVD without an effect on fat lowering $[45,46]$. On the other hand, interventional treatments with anakinra as a recombinant IL-1 receptor antagonist (IL-1Ra), rilonacept, and canakinumab suggested a significant pathological role of IL- $1 \beta$ in auto-inflammatory diseases [47]. Therefore, these studies provided evidence that IL-1 $\beta$ inhibition could improve the clinical outcome of CVD.

\section{NLRP3 Inflammasome and Its Role in Atherogenesis}

NLRs composed of 22 members are classified into functional sub-groups based on their N-terminal region. The most wellknown members of this family are NOD1, NOD2, and NLRP3, which primarily detect PAMPs and DAMPs ligands (Fig. 2). Unlike NOD1 and NOD2, most ligands of the NLRP3 are endogenous like DAMPs and signals that indicate host damage (e.g., metabolic stress, including cell necrosis, extracellular matrix components, and multiple host-derived molecules such as uric acid and cholesterol following their conversion to the crystalline state) [48]. The NLRP3 inflammasome plays a role in proteolytic processes and the maturation of IL-1 $\beta$ to its functional form. It functions as an essential sensor in the pathology associated with vascular endothelial dysfunction [49]. Recently, it was shown that excessive activation of NLRP3 represented a pivotal mechanism in the pathogenesis of metabolic diseases such as type 2 diabetes, obesity, gout, and atherosclerosis $[50,51]$. In vitro experiments have demonstrated that cholesterol is the most important signal for NLRP3 activation [52]. As shown in Fig. 1, two independent signals are required for NLRP3 activation: the initial signal is triggered via PRR receptors such as TLR and IL-1R, which activate the NF-KB pathway and result in transcription of NLRP3 and pro-IL- $1 \beta$. The second signal is oligomerization of activated NLRP3 and subsequently the recruitment of caspase-1 via 'apoptosis-associated speck-like protein containing a caspase recruitment domain' (Asc) adaptor. This process eventually causes the formation of the inflammasome, which ultimately leads to proteolytic cleavage and the activation of pro-inflammatory cytokines such as pro-IL-1 $\beta$ and pro-IL-18 [9]. 
a

$\begin{array}{lllll}\text { NLR Family } & \text { Symbol } \\ \text { NLRA } & \text { CIITA } & \text { NAIP } \\ \text { NLRB } & \text { NOD1, NLRC4 } \\ \text { NLRC } & \text { NLRC3, NLRC5, NLRX1 } \\ & \text { NLRP1 } \\ \text { NLRP2-9, NLRP11-14 } & \text { NLRP-10 }\end{array}$

b
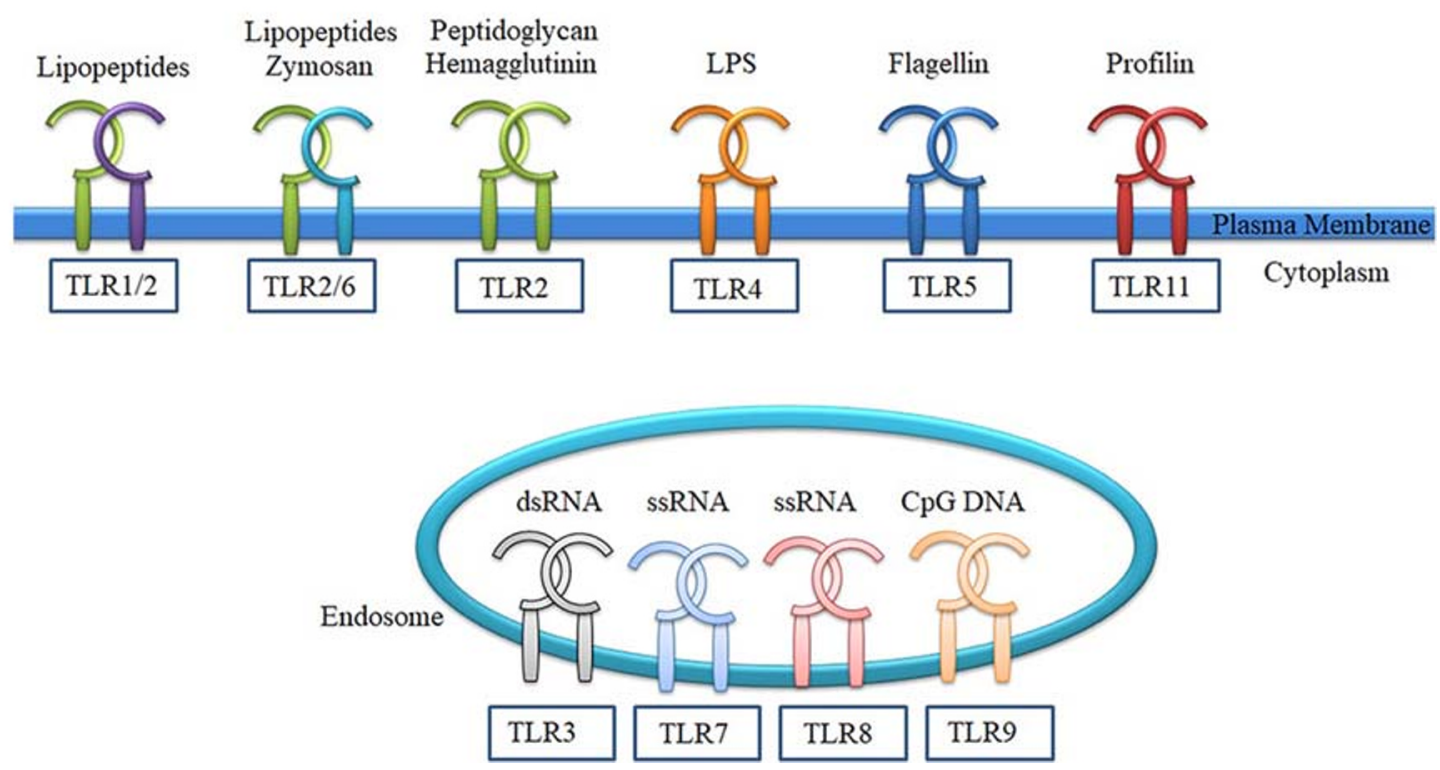

Fig. 2 The NLRs and TLRs families' structure. a The NLR families are divided into five sub-families including NLRA, NLRB, NLRC, NLRP, and NLRX. The symbols and structures of the 22 members are shown. $\mathbf{b}$ Cell surface and intracellular TLRs and their ligands. TLRs are divided into two groups based on their cellular localization. TLRs 1, 2, 4-6, and 11 localize to the cell surface and TLRs 3 and 7-9 reside at endosomal compartments. Cell membrane TLRs respond to microbial membrane antigens such as LPS, whereas endosomal TLRs recognize the virus and bacteria-derived nucleic acids (abbreviations: NLR: Nod-like receptor. CARD: caspase recruitment domain. PYD: pyrin domain. NACHT: nucleotide-binding and oligomerization domain. LRR: leucine-rich repeat. BIR: baculoviral inhibition of apoptosis protein repeat domain. NAD: NACHT-associated domain. AD: acidic transactivation domain. FIIND: domain with function to find. TLR: tolllike receptor. ssRNA: single-strand RNA. dsRNA: double-strand RNA. CpG DNA: CpG oligodeoxynucleotide. LPS: lipopolysaccharides) 
Both the mRNA and protein levels of NLRP3 in peripheral blood mononuclear cells (PBMCs) obtained from CAD patients are higher than non-CAD controls, which suggest that the transcription and protein levels of the NLRP3 inflammasome have a significant positive correlation with elevated plasma levels of IL-1 $\beta$ and IL-18 [41]. The NLRP3 knockout gene in experimental high-fat diet animal models shows a reduced production of IL-1 $\beta$ and IL-18 [43]. Additionally, studies have also shown that atherosclerotic plaques have higher NLRP3 mRNA, Asc adaptor, caspase-1, IL-1 $\beta$, and IL-18 levels [53]. In atherosclerotic plaques, components such as ox-LDL, CCs, extracellular ATP, and ROS may possibly be activating the NLRP3 inflammasome, which leads to inflammation and cellular infiltration $[54,55]$. Recent studies have also determined that the $\mathrm{P} 2 \mathrm{X} 7$ receptor (P2X7-R) that mediates ATP-dependent NLRP3 activation is significantly increased in coronary atherosclerotic lesions of $\mathrm{ApoE}^{-/-}$ and LDL- $\mathrm{R}^{-/-}$deficient mice, as well as in human carotid atherosclerotic plaque tissue $[56,57]$. Additionally, the P2X7-R knockdown in ApoE ${ }^{-/-}$[56] and LDL- ${ }^{-/-}$deficient mice [57] showed a decrease in the activation of lesional inflammasomes and the size of atherosclerotic plaques. Thus, this would seem to suggest that P2X7R is involved in the progression of atherosclerosis by promoting the activation of the NLRP3 inflammasome [58, 59].

The first experimental study that demonstrated the importance of NLRP3 activation in the development of diet-induced atherosclerosis was performed by Duewell P. et al. [19]. They transplanted the bone marrow of wild-type, $\mathrm{NLRP}^{-/-}, \mathrm{Asc}^{-1}$ ${ }^{-}$, IL- $1 \beta^{-/}$, IL- $1 \alpha^{-/-}$mice into LDL-R ${ }^{-/-}$mice. After 8 weeks of consuming a high-fat diet, they found that the $\mathrm{NLRP}^{-/-}$, $\mathrm{Asc}^{-/-}$, IL-1 $\beta^{-/-}$, and IL- $1 \alpha^{-/-}$mice showed a significant decrease in the number of atherosclerotic lesions. Their findings suggest that NLRP3, Asc, IL- $1 \beta$, and IL- $1 \alpha$ represent important inflammatory biomarkers in LDL- $\mathrm{R}^{-/-}$mice when compared to wild-type mice. This study also revealed the importance of NLRP3 activation in the development of atherosclerosis. Another study employing a caspase-1 knockout in a high-fat diet animal model showed a significant reduction in the formation of atherosclerosis plaques. Furthermore, other studies have shown that silencing IL- $1 \alpha$, IL- $1 \beta$, and caspase1 genes in the $\mathrm{ApoE}^{--}$mouse model can significantly decrease the development of atherosclerotic lesions [60].

Another study reported that bone marrow depletion of caspase-1 in LDL- $\mathrm{R}^{-/}$deficient rats consuming a high-fat diet had a significant reduction in atherosclerotic plaque formation, while other studies have shown that silencing IL- $1 \alpha$, IL- $1 \beta$, and caspase- 1 genes in $\mathrm{ApoE}^{-/-}$mice can significantly diminish the development of atherosclerosis [60]. In this regard, Menu P. et al. reported contradictory results; $\mathrm{ApoE}^{-/-}$ mice with a double-knockout each of $\mathrm{NLRP}^{-/-}, \mathrm{Asc}^{-1-}$, and caspase- $1^{-1-}$ and consuming a high-fat diet for 11 weeks neither influenced the progression of atherosclerosis, nor the progression in cell infiltration into the intima. Therefore, this study showed that the progression of atherosclerosis was independent of the activation of NLRP3-mediated inflammation [61]. Baldrighi M. et al. showed that these different results could be explained by the difference in the test conditions including the mouse model employed, gender, diet type, and the duration of the experiment [62].

In in vitro studies using THP-1 cell lines, it has been demonstrated that NLRP3 gene silencing using siRNA caused a decrease in IL-1 $\beta$ secretion in response to CCs [62]. Zheng F. et al. found that knockout of the NLRP3 gene in ApoEdeficient mice using lentiviral RNA interference reduced the level of inflammatory cytokines, the lipid content of macrophages in atherosclerotic plaque, and increased the content of collagen in platelets. It also reduced the vulnerability of the plaques to rupture. Therefore, this study demonstrated that NLRP3 plays an important role in the pathogenesis of plaque vulnerability and instability [63]. All of these data demonstrate the critical role of the NLRP3 inflammasome in the pathogenesis of cardiovascular disease, especially atherosclerosis. Thus, targeting this molecule may very well represent a potential therapeutic intervention in the treatment of CVDs.

\section{Structure, Function, and Role of TLRs in Atherosclerosis}

TLRs are part of the PRR family and identify unique patterns of microbial pathogens. These receptors are transmembrane proteins that possess a leucine-rich extracellular region and a conserved cytoplasmic region with homology to the IL-1 receptor, termed the Toll/IL-1 receptor homology region [64]. The TLR and IL-1 receptor members can potentially use the same signaling pathway [8]. TLR signaling stimulates the production of reactive nitrogen and oxygen species, antimicrobial peptides, inflammatory cytokines, adhesion molecules, and acute-phase proteins [64]. Thirteen distinct TLRs (TLR1-TLR13) have been identified in mammals. Some members of this family have been found in the plasma membrane (TLR-1, 2, 4, 5, 6, 10, and 11) while others are localized intracellularly (TLR-3, 7, 8, and 9) [65]. This distribution allows for the identification of a wide range of intracellular and cytoplasmic PAMPs (Fig. 2). Activation of TLR signaling can subsequently activate both innate and acquired immune responses through several mechanisms such as expression and release of inflammatory cytokines and anti-microbial peptides, dendritic cell (DCs) maturation, and up-regulation of co-stimulatory molecules on activated dendritic and $\mathrm{T}$ cells [66]. The TLRs can recognize endogenous ligands such as ox-LDL, HSPs, hyaluronan fragments, HMGB1, fibrinogen, beta-defensin, and heparan sulfate. These endogenous proteins are often released in response to stress or tissue damage at chronic inflammation sites. Therefore, due to the 
identification of self-ligands, TLRs may be involved in pathological inflammatory diseases such as atherosclerosis [8] (Fig. 1). Previous studies have shown up-regulation of TLR1, 2 and 4 in atherosclerotic plaques [64]. Specifically, previous studies have shown that ox-LDL can increase TLR4 expression without an effect on TLR2. This is probably due to ox-LDL acting as a ligand for TLR4 and eventually activating the NF-kB transcription factor, which leads to the synthesis of inflammatory cytokines and chemokines [20].

Previous studies have shown up-regulation of TLR1, 2, and 4 in atherosclerotic plaques [67]. In fact, it has been demonstrated that ox-LDL increase TLR4 expression without an effect on TLR2 expression. This is probably due to ox-LDL acting as a ligand for TLR4, and consequently signaling through the NF-kB transcription factor that leads to the synthesis of inflammatory cytokines and chemokines [20]. TLR4 signaling requires an adapter protein called MyD-88. MyD88deficient mice exhibit a significant decrease in inflammatory cytokines and chemokines in the early stages of atherosclerosis [68]. Also, it has been observed that inhibition of TLR4 activation can reduce plaque size and macrophage infiltration into atherosclerosis lesions [68]. Further evidence supporting the roles of TLR2 and TLR4 in atherosclerosis is the fact that TLR2 and TLR4 agonists can stimulate atherosclerosis in various mouse models [67, 69]. However, the role of endosomal TLR signaling pathways in atherosclerosis is not completely clear, because both pro- and anti-atherogenic properties of endosomal TLRs have been reported. In this regard, epidemiological studies have shown that cardiovascular risk is increased in individuals with chronic or recurrent bacterial infections [70] and increased concentrations of plasma LPS [71]. Thus, either infection or an increase in plasma LPS resulted in either TLR2 and TLR4 up-regulation on monocytes [72] or responsiveness of leukocytes to TLR2 and/or TLR4 ligands [73]. Recent studies have demonstrated that TLR signal transduction in immune cells is a potential therapeutic target in atherosclerotic cardiovascular disease. This is because enzyme and inflammatory cytokine production are directly related to increased TLR expression via NF-кB [74]. Therefore, these findings suggest that TLRs could be involved in inflammatory processes underlying atherosclerosis and may represent useful therapeutic targets in the treatment of CAD.

TLR4 is expressed at low levels by endothelial cells in the normal vessel wall, but increases in atherosclerotic plaques. This up-regulated TLR4 is often found in the rupture-prone shoulder of the atherosclerotic plaques [75] (Fig. 1). It has been shown that TLR4 is increased in macrophages in lipidrich atherosclerotic lesions. Also, ox-LDL leads to upregulation of TLR4 [76]. For the first time, Michelsen et al. showed a direct correlation between TLR4 signaling and the formation of atherosclerotic plaque. They observed that atherosclerosis was decreased in a TLR4 knockout hypercholesterolemic mouse model [77]. On the other hand, it has been determined that there is a reduction in neointimal formation in the 'early' stages of atherosclerosis in the absence of TLR4 signaling [78]. TLR2 signaling has also been demonstrated to be involved in the development of atherosclerosis [67]. In this regard, it has been reported that activation of endogenous TLR2 in mice may play a central role in the regulation of vascular inflammation, as well as subsequent neointimal formation in damaged vessels [79].

Currently, it hoped that the attenuation of the TLR signaling pathway may alter the progression of CAD. The PRIM study showed inconsistent results with the hypothesis that TLR4 polymorphisms such as D299G could reduce the risk of coronary events. This study determined that the D299G TLR4 polymorphism was not associated with CAD risk or any inflammatory disease [80]. Moreover, Yang et al. showed that the $\mathrm{D} 299 \mathrm{G}$ polymorphism is not associated with coronary artery stenosis [81]. The D299G polymorphism is located in the TLR4 region on chromosome 9 and correlated with diminished activity due to a defect in TLR4 signaling [82]. Kiechl et al. reported that the D299G polymorphism is associated with an increased risk of acute severe infection, but a decrease in atherosclerosis, carotid artery disease, and overall cardiovascular mortality [83]. Additionally, it has been shown that this polymorphism may affect lipid metabolism in addition to lowering pro-inflammatory status. Carriers with this polymorphism have a lower risk for cardiovascular events following statin therapy in comparison to non-carriers [84]. In contrast with its protective effects, it has also been shown that D299G polymorphism can increase the risk of MI in men. The results of a 3-year follow-up study by Labrum et al. showed no association between the polymorphism and the progression of intima-media thickness (IMT) [85]. Another study with young male and female Finns did not show an association between the D299G polymorphism and carotid artery IMT. However, this group reported an association between the polymorphism and carotid artery elasticity which may involve incomplete TLR4 signaling [86].

\section{Statins and Their Mechanisms of Action}

\section{Mechanisms of Action in Atherosclerosis}

Among a wide class of conventional and novel lipid-lowering therapies [87, 88], statins are the most commonly used effective drugs to treat hyperlipidemia in CVDs. These classes of drugs affect the mevalonate pathway through competitive inhibition of the rate-limiting enzyme in cholesterol neosynthesis called 3-hydroxy-3-methylglutaryl coenzyme A (HMG-CoA) reductase. HMG-CoA reductase converts mevalonate to cholesterol in the liver and other tissues and reduces reductase gene expression through negative feedback [89]. As a result, these drugs lead to a reduction in the 


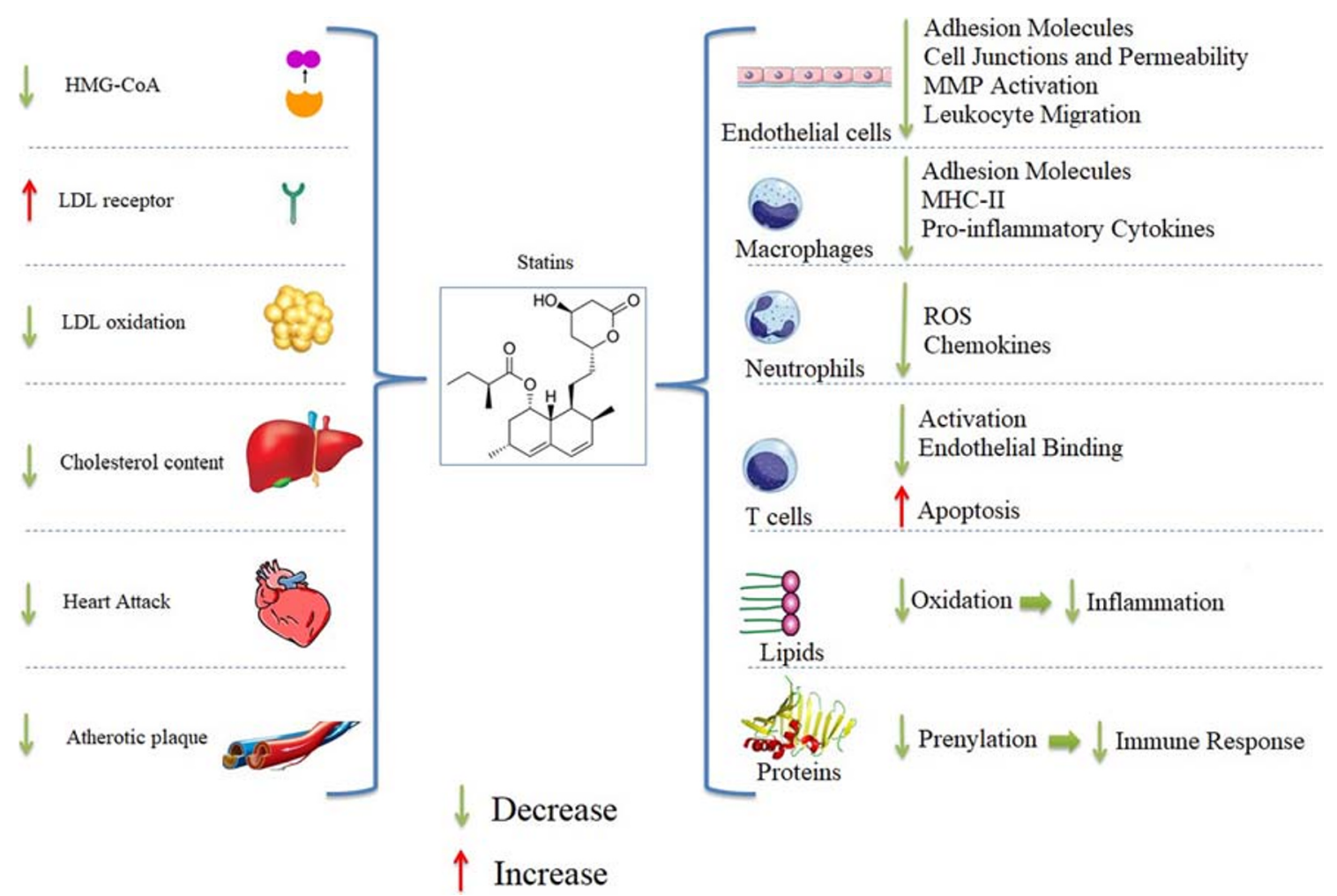

Fig. 3 The effects of statins in atherosclerosis (a) and the immune system (b) (abbreviations: HMG-CoA: 3-hydroxy-3-methyl-glutaryl-coenzyme A. MMP: matrix metalloproteinases. ROS: reactive oxygen species. MHC-II: major histocompatibility complex-II. LDL: low-density lipoprotein)

cholesterol content in liver cells, and also cause increased expression of the LDL receptor on the cell surface that leads to a decrease in plasma LDL levels. Additionally, the normal functioning of the LDL receptors helps to maintain a normal concentration of intracellular cholesterol [90]. Moreover, statins can reduce plasma triglyceride levels without effect on the concentration of lipoprotein-A [91] (Fig. 3). Finally, several pleiotropic actions independent of their established lipid-lowering effects have been described for statins [92-96].

Hydrophilic statins such as pravastatin and fluvastatin do not easily penetrate into the cell membrane which results in less pleiotropic properties and fewer potential side effects for the central nervous system (CNS) and muscle. On the other hand, lipophilic statins such as simvastatin, lovastatin, and atorvastatin have more pleiotropic effects and side effects [94]. Overall, two generations of statins exist; natural statins (e.g., lovastatin, simvastatin, and pravastatin) and synthetic statins (e.g., fluvastatin, atorvastatin, and rosuvastatin), which have different pharmacokinetic properties, lipid-reducing properties, and complications with chronic use [97]. Although all of the statins reduce LDL, they have different effects on lowering cholesterol, the incidence of cardiovascular events, and the development of atherosclerosis. For example, pravastatin can reduce mortality in those who have had MI or experience unstable angina [98]. This difference may be due to either non-lipid agents, or non-cholesterol-dependent effects [99]. The most effective statin drugs in terms of reducing LDL and triglyceride levels are atorvastatin and rosuvastatin, respectively [100]. Higher doses of statins are more effective than lower doses for profound LDL reductions and eventually lead to reduced coronary artery diseases risk [101].

Statins are effective in preventing both primary and secondary cardiovascular disease. Large-scale randomized clinical trials showed beneficial effects of statins at reducing mortality in atherosclerosis patients, as well as a significant reduction of non-lethal vascular events [102, 103]. It has been suggested that the remarkable and significant beneficial effects may partly be due to the lowering of cholesterol levels, and other properties beyond cholesterol-lowering [104]. Since atherosclerosis has been identified as an inflammatory disease [105], extensive clinical studies have been performed and have shown potent anti-inflammatory effects of statins in the treatment of atherosclerosis [106]. Generally, the beneficial effects of statins in CVD are due to optimization of the lipid profile, inhibition of LDL oxidation, anti-inflammatory functions, inhibition of migrating immune cells, and inhibition of proliferation of smooth muscle cells. In addition, statins mediate antiatherosclerotic properties by preventing the development of new lesions and stabilizing existing plaques via a reduction in the expression of tissue factor (TF). Moreover, statins indirectly 
cause an increase in endothelium-derived nitric oxide production and a reduction in platelet aggregation, which leads to a reduction in the risk of acute coronary events [107, 108].

\section{Mechanism of Actions in the Immune System}

Beyond the role of reduced fats, statins have effects on the immune system. As shown in Fig. 3, their prominent effects include anti-inflammatory, anti-oxidant, anti-apoptotic, and are tissue-protective in some pathological conditions [109]. Statins affect the innate immune system through their effects on endothelial cells, macrophages, natural killer cells, and neutrophils, while they influence the acquired immune system by inhibiting antigen presentation and $\mathrm{T}$ cell polarization [110]. Evidently, the most predominant non-lipid-lowering effect of statins that has been reported includes their antiinflammatory properties, which are multifaceted in nature. For example, some of these effects are due to the reduction of upstream mediators from cholesterol biosynthesis in the mevalonate pathway and, consequently, there is a reduction of protein prenylation that affects the immune response [110]. Decreased protein prenylation leads to a shift of the immune response to an anti-inflammatory response accompanied by a reduction in TNF and IL-6 levels in peripheral blood as seen in various LPS-treated animal models. It has been demonstrated that statins can reduce the activity of transcription factors such as NF-KB and activator protein-1 (AP-1), which are involved in regulating inflammatory pathways such as IL-1 $\beta$ [111]. Importantly, statins exert anti-inflammatory effects on several cells that are involved in the development and rupture of atherosclerotic plaques $[112,113]$.

Recent clinical trials have shown beneficial effects of statins in the reduction of inflammation. Statins reduce Creactive protein (CRP) [114-116] as an acute-phase protein $[117,118]$. Also, statins disrupt other inflammatory processes such as expression of cell adhesion molecules, inhibition of leukocyte migration to the sub-endothelial space, MHC-II down-regulation, and reduction in the CRP and TNF- $\alpha$ levels [114-116]. These observations suggest that statins can be used for other inflammatory conditions such as inflammatory arthritis [119, 120], diabetes [121], asthma [122], sepsis [123], and neurodegenerative diseases such as Alzheimer's disease (AD) [124].

\section{The Effects of Statins on NLRP3 in CVD: Inhibitory or Stimulatory Effects}

Several studies investigated statin effects on IL-1 and the NLRP3 inflammasome. It showed that statins such as simvastatin can reduce cytokine production in monocytes under TLR-stimulated conditions in patients with hypercholesterolemia $[125,126]$. Statin therapy can down-regulate
NLRP3, cathepsin-B, and downstream mediators such as IL$1 \beta$, which play a significant role in inflammation associated with atherosclerosis and reduce NLRP3 gene expression in PBMCs of CVD patients [59]. On the other hand, several studies demonstrated that statins can enhance IL-1 $\beta$ expression in response to LPS under the absence of any NLRP3 inflammasome stimuli $[127,128]$. In addition, statins can enhance caspase- 1 activity and promote IL- $1 \beta$ activation. This effect was initially reported to be associated with simvastatin and no other statins. Interestingly, this effect has now been reported to be associated with an increased risk of diabetes in some patients that have received statin therapy [129].

The exact anti-inflammatory effects of statins are incompletely understood. Several studies showed that the antiinflammatory effects of statins are exerted through the suppression of inflammasomes. Various investigators demonstrated that the effect of statin therapy on the NLRP3 inflammasome is varying and significantly dependent on the type of statin used. There are inconsistent data on the effects of statins on inflammasome and caspase-1 activation. Some studies suggest that statins activate inflammasomes and caspase-1 [129-135]. In contrast, other studies have reported that statins interfere with the activation of inflammasomes and caspase-1 [41, 59, 106, 136]. Therefore, NLRP3-related IL$1 \beta$ expression through statins remains controversial and their exact mechanism(s) is unknown. In the next section, we discuss the primary effect(s) of statins on the NLRP3 inflammasome (Table 1 and Fig. 4).

Since macrophages and foam cells within atherosclerotic plaques predominantly express NLRP3 inflammasome components $[151,152]$, the role of NLRP3 inflammasome activation in the pathogenesis of atherosclerosis has been the primary focus. Kong F. et al. investigated the effect of atorvastatin on human THC-1 monocyte cell lines and reported that atorvastatin can inhibit NLRP3 expression, disrupt the activity of caspase-1, and eventually interfere with the secretion of IL- $1 \beta$ in these cells. This group suggested that the inhibitory mechanism of atorvastatin was through suppression of the TLR4/MyD88/NF-кB pathway [137]. These results support the effects of atorvastatin on NLRP3, and ultimately, on IL$1 \beta$ expression, and suggest that atorvastatin may represent a promising agent in the treatment of atherosclerotic plaque. As mentioned, TLR4 plays an important role in initiating inflammation associated with atherosclerosis [153-156]. MyD88, as an important adaptor in the TLR4 signaling pathway, has subsequent regulatory effects on NF-kB [157].

$\mathrm{NF}-\mathrm{KB}$ is an important factor that regulates the expression of many genes that are involved in inflammatory responses and effect atherosclerotic lesion development. Moreover, this factor influences the expression of genes involved in vascular diseases that could influence cell migration, promote inflammation, and the balance between cell proliferation and apoptosis [158, 159]. Interestingly, it has been suggested that 


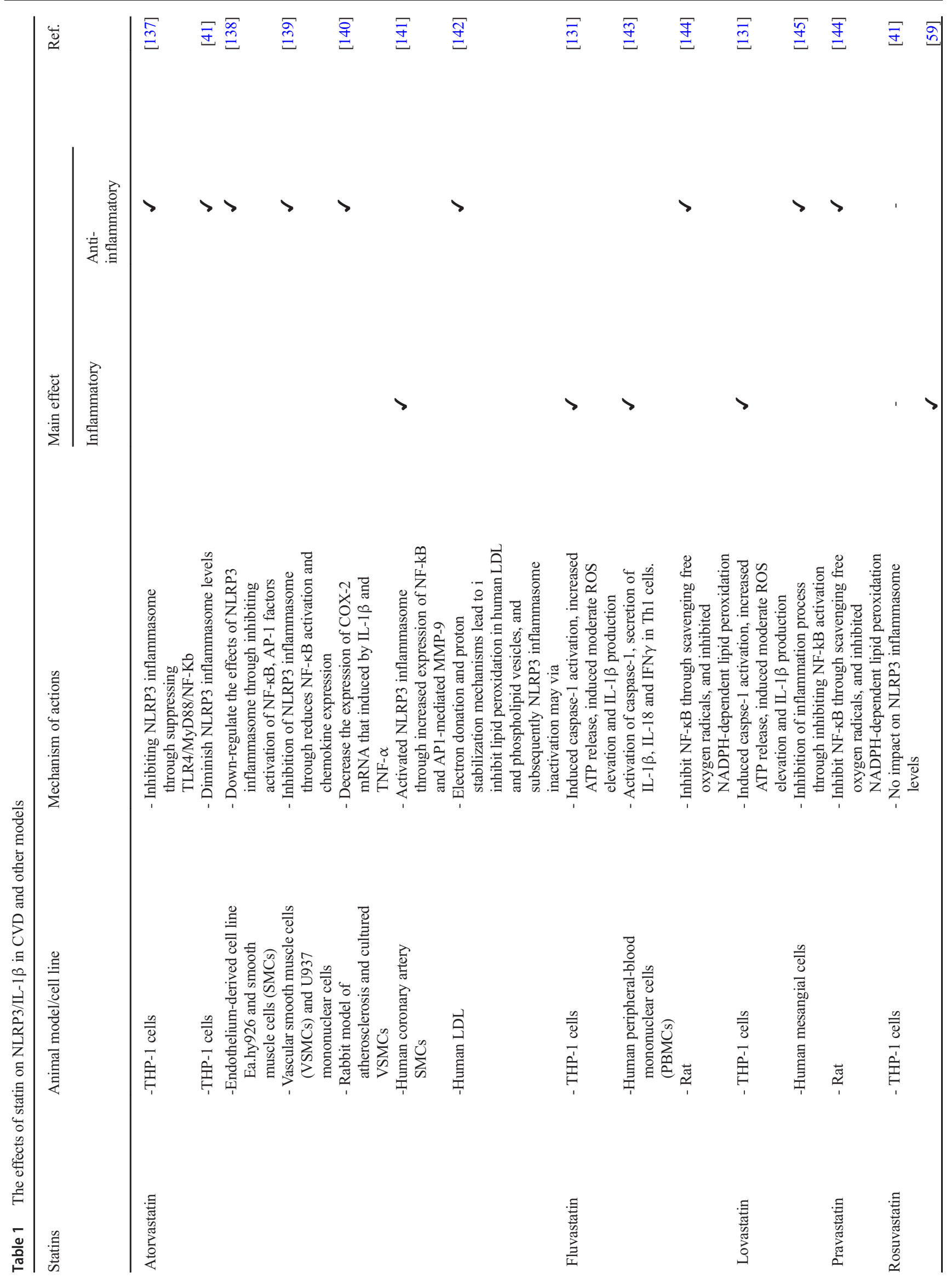




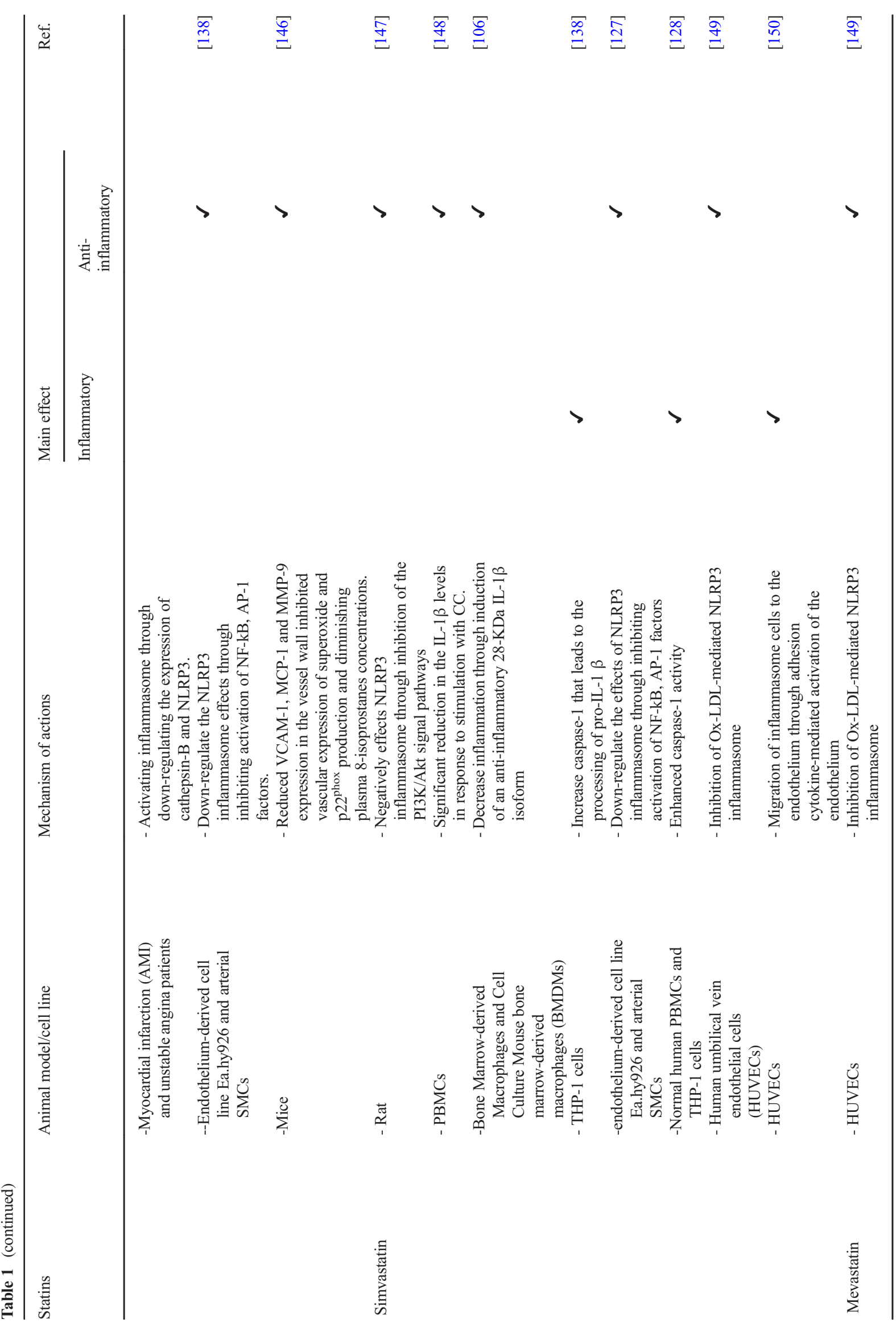




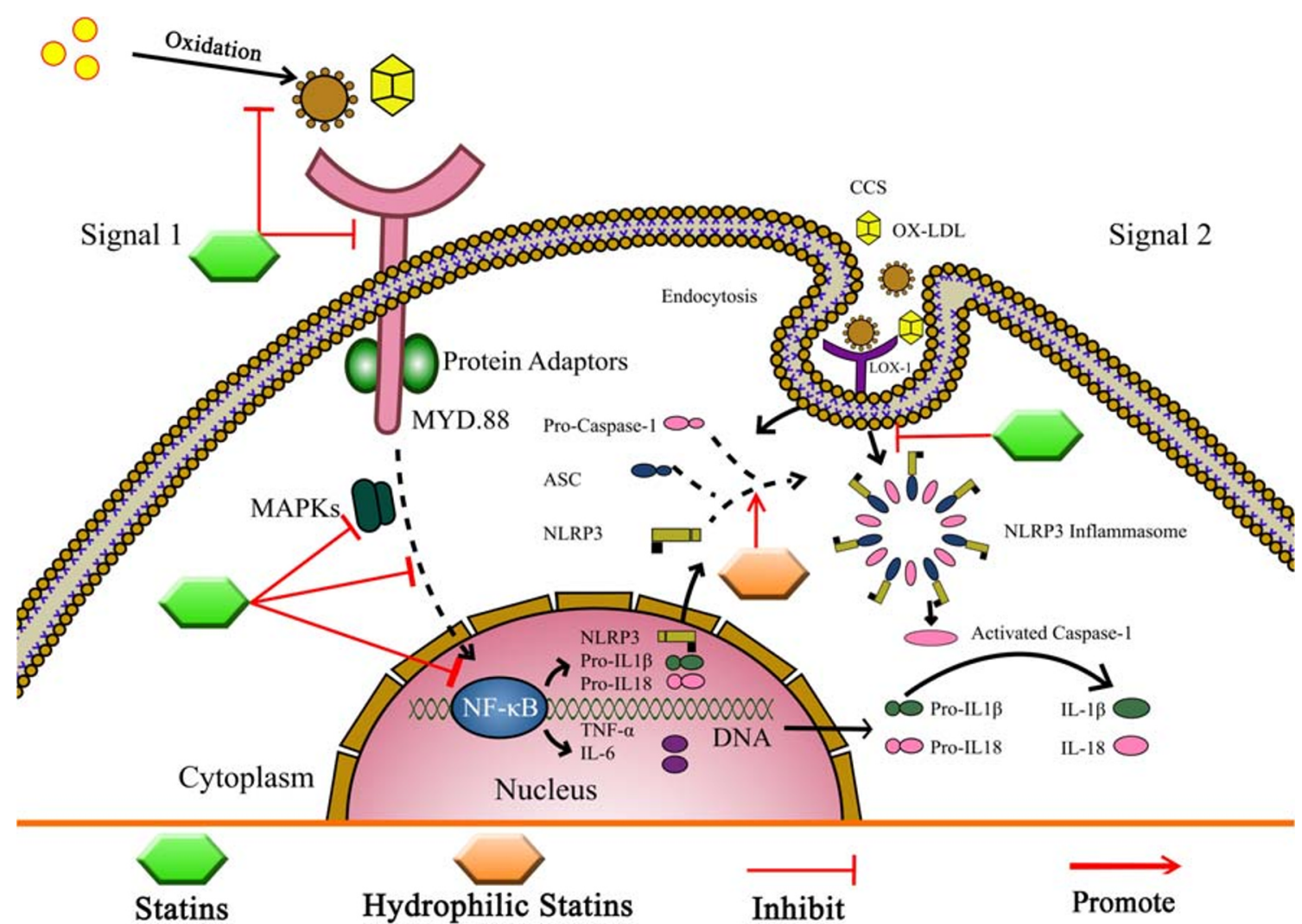

Fig. 4 The effects of statin on NLRP3 inflammasome and TLRs pathways. It appears that the effects of statins on NLRP3 complex are related to chemistry and pharmacokinetics features. Lipophilic statins have more pleiotropic effects on NLRP3 complex compare than hydrophilic statins. In the other hand, statins with inhibition of the mevalonate pathway, the protein prenylation or lipidation, and decreases cholesterol production caused reduce TLR agonists and suppressing TLR4/MyD88/NF-кB pathway. Also, statins inhibit NF-кB through reduce MAPKs phosphorylation and stabilized IKB- $\alpha$ as an NF$\mathrm{\kappa B}$ inhibitor. Statins inhibit expression of LOX-1 receptor; therefore, they could inhibit the inflammation of NLRP3 through LOX-1/NF-KB pathway. The diabetes basic risk, metabolic syndrome, genetic, and lifestyle could promote NLRP3 inflammasome in presence statins. The

blocking of NF-kB in vivo can prevent MI [160]. Statins inhibit NF-KB by scavenging free oxygen radicals and also stimulating the production of nitric oxide, which can subsequently induce and stabilize IKB- $\alpha$ as an NF-KB inhibitor [144, 161]. Studies have shown inconsistent results regarding the effects of statins on NF-KB. Some studies have demonstrated that atorvastatin reduces the activation of NF-KB in mononuclear cells and smooth muscle cells [139], as well as decreases NF-KB activity in experimentally induced atherosclerotic lesions in rabbits [140]. Moreover, it has also been shown that lovastatin reduces NF-KB activation in mesenchymal cells [145] and other statins, such as simvastatin, lead to an increase in NF-KB activation in endothelial cells [150]. In a study by Dichtl et al., it was demonstrated that statins such as simvastatin, atorvastatin, and lovastatin reduce the activation of hypoxia-inducible factor-1 (HIF-1), NF-KB, and AP-1 in statin could decrease the expression of TLRs 2 and 4, so suppressed NF$\mathrm{\kappa B}$ activity. At the genetic and molecular level, the TLR4 D299G polymorphism contributes in less susceptibility to cardiovascular disorders and increase response to statin therapy; also, statin therapy has a positive effect on miRNAs levels which affected on TLRs and negatively regulated TLR4 (abbreviations: LDL: low-density lipoprotein. OXLDL: oxidized LDL. NLRP3: Is a NLRs. CCs: cholesterol crystals. NF-кB: nuclear factor kappa-light-chain-enhancer of activated B cells. Asc: apoptosis-associated speck-like protein containing a CARD. MAPKs: mitogen-activated protein kinase. TNF$\alpha$ : tumor necrosis factor- $\alpha$. IL: interleukin. Lox-1: lectin-type oxidized LDL receptor-1. MyD-88: myeloid differentiation primary response-88)

vascular and endothelial muscle cells. Therefore, the use of these statin drugs for their anti-inflammatory and antiproliferative effects has been encouraged for the treatment of atherosclerotic heart disease [138]. Further studies have supported the anti-inflammatory role of statins, such as with atorvastatin, which inhibits the NF-KB pathway in the human coronary artery [141] and in various experimental animal models [162].

A randomized clinical trial was conducted by Satoh M. et al. on $60 \mathrm{CAD}$ patients who had no prior history of statin therapy and then assigned either of two statins (atorvastatin or rosuvastatin). The patients were followed for 8 months. They showed that NLRP3 inflammasome levels in CAD patients were higher than control subjects and there was a positive correlation between the increased levels of NLRP3 and IL$1 \beta$ and IL-18 [41]. This study confirmed that atorvastatin, 
but not rosuvastatin, markedly decreased the expression and activation of the NLRP3 inflammasome, as well as the plasma levels of IL-1 $\beta$ and IL-18 in CAD patients. However, the in vitro studies with THP-1 cells showed that treatment with both atorvastatin and rosuvastatin affected NLRP3, IL-1 $\beta$, and IL-18 supernatant levels in a dose-dependent manner. However, rosuvastatin had a less significant effect on IL-1 $\beta$ and inflammasome levels when compared to atorvastatin [41]. The reason for this difference is not clear, but Mason et al. showed that atorvastatin is more lipophilic than rosuvastatin and exhibits better cell penetration. Notably, it was shown that atorvastatin exhibits a powerful antioxidant effect in comparison to other statins such as pravastatin, rosuvastatin, and simvastatin [142]. However, another clinical study by Koksal et al. in diabetic patients with hyperlipidemia did not show any difference between atorvastatin and rosuvastatin in terms of attenuating oxidative stress [163]. The reason for this difference may be due to the dose of rosuvastatin that was used ( $2.5 \mathrm{mg} /$ day versus $10 \mathrm{mg} /$ day).

Various animal models have shown cardioprotective effects of rosuvastatin in myocardial infarction, autoimmune myocarditis and experimental hypertrophy [164-166]. The protective mechanisms of rosuvastatin against dilated cardiomyopathy (DCM) have not yet been fully elucidated. In a study by Luo et al. using a DCM rat model in the context of experimentally induced type 2 diabetes mellitus, 8 weeks of treatment with rosuvastatin resulted in a decrease in the levels of NLRP3, Asc adaptor, IL-1 $\beta$, and mitogen-activated protein kinases (MAPKs) in cardiac tissue [136]. They observed that cardiac disorders caused by diabetes in the rosuvastatin-treated group were prevented, while this effect was minimal in downregulated NLRP3 rats. Thus, it was suggested that rosuvastatin may exert a protective effect and decrease cardiovascular morbidity, which is dependent on inhibiting the NLRP3 inflammasome. Importantly, MAPKs are also critical signaling pathways in cardiac remodeling associated with DCM $[167,168]$. In fact, several studies have suggested that enhanced phosphorylation of MAPKs can be normalized by rosuvastatin $[169,170]$, which has been suggested to be linked to the inhibition of MAPK. This is consistent with previous studies, which have suggested that an increase in the activation of ERK1/2, P38, and JNK may worsen the functional and structural performance of cardiomyocytes in diabetic rats. In a study by Luo et al., it was mentioned that treatment with rosuvastatin inhibited hyper-phosphorylation of MAPKs and could improve cardiac function. Therefore, rosuvastatin appears to be extremely beneficial, at least in diabetic rats, in improving cardiac performance [136].

Oxidized-LDL receptor 1 (LOX-1) is a lectin-like receptor and is a major ox-LDL receptor in epithelial cells. Moreover, it is a biomarker for many CVDs $[171,172]$ and increases in response to many atherogenic stimuli such as TNF $\alpha$, ox-LDL, and free radicals [171]. Activated LOX-1 can lead to the production of ROS, mitochondrial DNA damage, and finally, induction in the expression of NLRP3 [173]. LOX-1 deletion in epithelial cells results in reduced NLRP3 activation through ox-LDL. Wang et al. suggested a new mechanism for the beneficial effects of statins as cardiovascular drugs. This group showed that statins (simvastatin, mevastatin, and atorvastatin) activated pregnane $\mathrm{X}$ receptors (PXRs) in epithelial cells. Silencing the PXR gene leads to elimination in the inhibitory effect of statins on NLRP3-mediated inflammation, whereas PXR agonists or excessive expression of PXR provides a similar effect to statins on NLRP3. For the first time, they showed that statins can inhibit the activation of NLRP3 inflammasomes in response to atherogenic stimuli such as ox-LDL and TNF $\alpha$ in epithelial cells via activation of the nuclear receptor PXR [149].

Following binding of ox-LDL to endothelial LOX-1, the NF-KB pathway is activated. Importantly, statins inhibit LOX1 expression in a PXR-dependent state. Therefore, statins can inhibit the inflammation of the NLRP3 inflammasome in epithelial cells via the LOX1-/NF-KB pathway. These results show the important role of ox-LDL and LOX-1 in NLRP3 inflammasome activation. In addition, the effect of statinactivated PXR on the binding of NF-KB to the human NLRP3 promoter has been investigated, and the results showed that statin-activated PXR prevents NF-KB binding to the NLRP3 promoter in epithelial cells. In chromatin immunoprecipitation experiments, it has been shown that mevastatin inhibits the NF-KB binding to the promoter region of the human NLRP3 gene. Since NF-KB has a central role in regulating NLRP3 gene transcription, it follows that PXR inhibits the activation of NF-KB genes.

In a study by Lv et al., it was shown that simvastatin leads to inactivation of the NLRP3 inflammasome by inhibiting the secretion of HMGB1, as one of the major DAMPs that can activate the NLRP3 inflammasome. This reduction in HMGB1 secretion improves the functioning of tight junctions and vascular permeability. In fact, this study showed that simvastatin, by enhancing the tight junction-zonula occludens-1 (ZO-1) and VE-cadherin (VE-cad)-based adherens junctions in the endothelial cell layer, leads to an increase in permeability of the endothelial cell layer. Moreover, simvastatin can inhibit the NLRP3 inflammasome by influencing NADPH oxidase-dependent $\mathrm{O}_{2}$ production [174]. This result is consistent with other studies, which suggested that endogenous ROS participate in the formation and activation of the NLRP3 inflammasome [175]. This effect was accompanied by simvastatin's inhibitory effect on the release of HMGB1, which leads to improved tight junctions in the vascular site and enhances our understanding of the anti-inflammatory effects of statins on vascular pathology beyond their lipidlowering effects. In one study that investigated the protective effect of statins against ischemia-reperfusion (IR), the mechanism for the beneficial effects of statins was not completely elucidated. Han et al. investigated the effect of simvastatin on 
HMGB1 expression in myocardial ischemia. They demonstrated that simvastatin has a protective role in the heart against IR damage by reducing HMGB1 protein levels and attenuating the PI3K/Akt signaling pathway [147]. In other studies, it was shown that the 16673-34-0 molecule, an intermediate subunit in glyburide synthesis, leads to inhibition of both NLRP3 inflammasome formation in myocarditis and the infarct size resulting from myocardial ischemia, without affecting glucose metabolism [176]. Another study showed that NLRP3 was identified as an important target for ROS in terms of attenuating the inflammatory response in diabetic cardiomyopathy [53]. Therefore, it is believed that statins protect the heart against IR by inhibiting the NLRP3 inflammasome.

Several reports have shown that statins can increase the expression of IL-1 in response to LPS [127, 128]. However, the effect of statin therapy on NLRP 3 activation by stimulants such as CCs was not investigated. Boland et al. examined the inhibitory effect of simvastatin on IL- $1 \beta$ expression and utilized CCs as a stimulator of NLRP3 in PBMCs of a cardiovascular animal model. These investigators found that statin therapy can enhance the activation and expression of IL- $1 \beta$ in response to NLRP3 stimulants and suggested that simvastatin exerted inhibitory effects on the NLRP3 inflammasome following stimulation of the NLRP3 pathway by CCs [148]. However, it would seem that additional studies are needed to investigate the underlying molecular mechanism(s) to more clearly elucidate the effects of simvastatin following activation of the NLRP3 pathway by CCs. The reported effects of statins on IL- $1 \beta$ are potentially controversial due to the existence of different IL- $1 \beta$ isoforms. Pro-IL-1 is a $31 \mathrm{kDa}$ protein that is secreted as an active $17 \mathrm{kDa}$ form by caspase- 1 following inflammasome activation. Since currently used analytical methods in these studies cannot distinguish between IL- $1 \beta$ forms, it is unclear whether the secreted IL- $1 \beta$ form is the biologically active form. Davaro et al. suggested that statins suppress inflammation through an anti-inflammatory form of IL-1 $\beta$. In fact, they mentioned a new signaling pathway following inflammasome activation by LPS 'priming', which resulted in the production of a $28 \mathrm{kDa}$ IL- $1 \beta$ isoform that was independent of caspase- 1 . This $28 \mathrm{kDa}$ isoform is an intermediate of the IL- $1 \alpha$ isoform and is not biologically activated, but it does interfere with IL-1/IL-1R signaling [106].

Long-term treatment with ticagrelor, an antiplatelet medication, reduces cardiovascular events in patients with acute coronary syndrome $[177,178]$. Ticagrelor, like statins, enhances the levels of extracellular adenosine, which increase the amount of prostacyclin and 15-Epi-lipoxin A4 [179, 180]. Certain clinical benefits may be related to the effects of adenosine, including the release of 15-Epi-lipoxin A4. In previous studies, the anti-inflammatory properties of ticagrelor were shown [181], but its effect on NLRP3-mediated inflammation has not been reported. A recent study by Birnbaum et al. found that ticagrelor reduced the up-regulation of NLRP3, Asc, IL$1 \beta$, IL-6, and caspase-1. This effect in combination therapy with rosuvastatin was significantly greater than either rosuvastatin or ticagrelor monotherapy [180]. This combination therapy also had a synergistic effect on inhibiting NLRP3 post-infarction and reducing myocardial infarction in an experimental rat model [182]. Recently, adenosine-related cardioprotective effects have also been confirmed in a large-species animal model (pigs) [183]. Yume et al. indicated that long-term use of ticagrelor alone decreased the serum level of IL- $1 \beta$, IL-6, and TNF- $\alpha$, while the combination with rosuvastatin leads to a significant reduction in IL-1 $\beta$, IL-6, TNF- $\alpha$, and CRP levels [184].

\section{The Effect of Statins on TLR4 in Atherosclerosis}

It has long been thought that targeting TLRs to limit inflammatory disease might be a safe strategy. However, long-term use of TLR inhibitors may increase the risk of infection. Genetic evidence has suggested that TLR signaling, especially through either TLR2 or TLR4, is likely to alter the risk of CAD in humans [185]. Various studies have been conducted to determine the effect of statins on TLRs and downstream signaling in CAD. In this regard, statin therapy has been shown to decrease the expression of TLR4 on immune cells, decrease monocyte inflammatory responses to LPS via downregulation of TLR4, and suppress NF-KB activity, which caused a decrease in the secretion of inflammatory cytokines $[139,186]$. Additionally, statins, by inhibiting TLR4, can prevent LPS-induced activation of mononuclear cells and endothelial cells [187], decrease membrane expression of TLR4 and TLR2, and subsequently, inhibit the activity of LPSactivated monocytes in hyper-cholesterolemic patients [126] (Table 2 and Fig. 4).

The effects of co-administration of atorvastatin and mevalonate in an LPS-stimulated mouse model resulted in a decrease in NF-KB activation and inhibition of TLR4. The underlying mechanism used to explain this effect was a defect in the recruitment of TLR4 to the lipid raft [188]. Additionally, atorvastatin exerts effects on the atherosclerotic plaque by controlling lipid regulation and inhibiting TLR4 expression, as well as affecting P65 NF-kB in the TLR4/NF-kB signaling pathway [189]. Yang et al. showed that atorvastatin (ATV) can inhibit TLR4 protein levels, as well as inhibit TLR4 at the level of gene transcription. As a result, atorvastatin decreases TNF- $\alpha$, IL-6, and IL-1 $\beta$ levels in LPS-stimulated THP-1 monocytes [190]. Following approximately 4 weeks of atorvastatin administration, TLR4 expression was significantly reduced in $\mathrm{CD} 14^{+}$monocytes in vivo and in vitro in a dosedependent manner. Its mechanism of action is thought to 


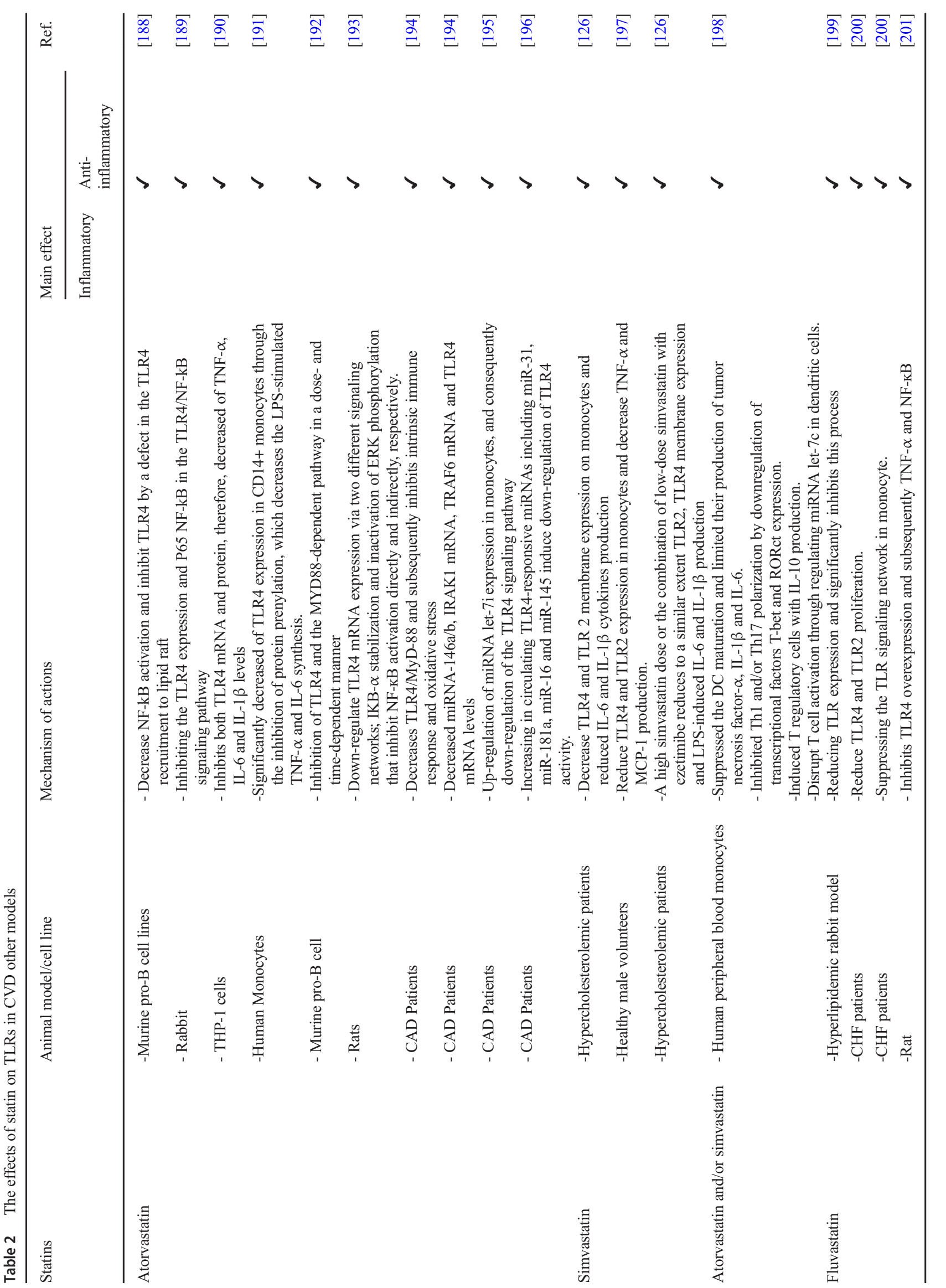


involve the inhibition of protein prenylation, which decreases the synthesis of LPS-stimulated TNF- $\alpha$ and IL-6 [191].

MyD-88 is one of the most important players in the TLR4 signaling pathway, which participates in the pathophysiology of myocardial injury [202]. It has been shown that the protective effects of atorvastatin on cardiomyocytes result from a decrease in TLR4/MyD-88 and subsequent inhibition of the intrinsic immune response and reduction in oxidative stress in injured rat myocardium [193]. In other studies, it has been shown that atorvastatin has an anti-inflammatory effect on atherosclerosis through TLR4 and the MYD88-dependent pathway in a dose- and time-dependent manner [192]. Wang et al. showed that atorvastatin down-regulated TLR4 mRNA expression through two different signaling networks; IKB- $\alpha$ stabilization that directly inhibits NF-KB activation and a second pathway that involves inactivation of ERK phosphorylation, which indirectly inhibits NF-кB activation [203]. Highdose administration of simvastatin has been demonstrated to decrease TLR4 and TLR2 membrane expression on monocytes and subsequently reduce the production of IL- 6 and IL-1 $\beta$ cytokines [126]. Moreover, the statins, via TLR4, can mediate the stabilization of atherosclerotic plaques. Use of statins leads to TLR4 down-regulation on macrophages and endothelial cells in carotid atherosclerotic plaques, which is associated with a reduced risk of cerebrovascular ischemic events [204]. For the first time, Kapelouzou et al. have shown that the expression levels for TLR2, 3, 4, and 8 were significantly increased and correlated with the development of atherosclerosis in an experimental hypercholesterolemic rabbit model. Fluvastatin significantly inhibited this process and decreased inflammation by reducing TLR expression, which was strongly associated with an alteration in plaque regression and a decrease in the levels of various mediators involved with atherosclerosis [199].

Chronic heart failure (CHF) is a disorder that primarily affects the cardiovascular system. It has been shown that there is an increase in TLR4 and cytokines in the heart tissue of patients suffering from CHF [205, 206], whereas TLR2 is increased in myocardial dysfunction in mouse models [207]. TLR 2 and 4 are highly-expressed in CHF and increased TLR4 expression is an essential feature in the progression of CHF. In a study by Földes et al., it was shown that TLR4 and TLR2 were increased in CHF patients and that fluvastatin reduced the levels of TLR 4 and TLR2 in monocytes ex vivo over $24 \mathrm{~h}$. Based on their findings, fluvastatin suppressed the monocyte TLR-signaling network and restrained the innate immune response in CHF patients [200]. Therefore, the use of an appropriate dose of fluvastatin in patients would presumably decrease myocardial TLR4 expression and could potentially exert a cardioprotective role by attenuating the inflammatory response. Importantly, fluvastatin has been shown to significantly reduce MI/RI by inhibiting TLR4 overexpression and subsequently reduce TNF- $\alpha$ and NF-kB [201]. Furthermore, simvastatin administration in high doses for 4 days was shown to reduce the expression of TLR 4 and TLR2 in monocytes and decrease TNF- $\alpha$ and MCP-1 levels [197]. This effect is significant, because TNF- $\alpha$ and MCP-1 are essential for the progression of atherosclerosis [208, 209].

TLR4 polymorphisms may affect and modulate the effectiveness of statin therapy. In this regard, it has been shown that TLR4 and statin (either simvastatin or pravastatin) exerted a synergistic inhibitory effect not only on LPS-induced NF-KB activation, but also on the expression of IL- 6 and TNF $\alpha$. Therefore, this may represent an explanation concerning genetic epidemiological studies, which have suggested that the beneficial effect of statins for cardiovascular risk is dependent on the TLR genotype [210]. Among symptomatic men with coronary artery disease, this TLR4 variant modifies the efficacy of pravastatin in preventing cardiovascular events [84]. In a study by John et al., it was shown that patients who were carriers of D299G genotypes had less susceptibility to myocardial infarction when receiving statin treatment. These findings suggested that TLR4 gene variations contribute to interpatient variation in susceptibility to coronary ischemic events, as well as the TLR4 genotype and statin therapy may have synergistic effects [75] (Table 2 and Fig. 4).

Notably, miRNAs can also regulate the effect of statins on the TLR4 pathway. The miRNA let-7i targets TLR4 mRNA and has a negative effect on the expression of this receptor that regulates the innate immune response in mammals [28]. It has been shown that miRNA let-7i levels in monocytes of CVD patients are decreased in comparison to non-CVD patients and results in increased TLR4 mRNA levels in the CVD patients. Thus, this finding suggested that down-regulation of let-7i is probably associated with overexpression of TLR4 in CVD patients [195]. Interestingly, the use of atorvastatin had a positive effect on miRNA let-7i levels in patients with CVD. However, rosuvastatin did not affect either miRNA let-7i or TLR4 levels. It appears that the beneficial effects of atorvastatin resulted from its lipophilic properties [195]. Additionally, it has been reported that plasma levels of circulating TLR4-responsive miRNAs including miR-31, miR-181a, miR-16, and miR-145 were decreased in CAD patients, which may suggest their involvement in the pathogenesis of atherosclerosis. Thus, combination therapy with a statin and RAS blockade (i.e., using either an ARB or ACEI) to increase circulating TLR4-responsive miRNAs would potentially induce down-regulation of TLR4 activity in CAD patients [196].

\section{Other Mechanisms of Statins on Inflammatory Pathways}

Another mechanism of action of statins on activating immune cells is by abolishing TGF- $\beta$ signaling in T cells, which leads to a decrease in plaque size [211]. Importantly, dendritic cells 
are involved in various stages of atherosclerosis as specialized antigen-presenting cells [212]. It is also known that ox-LDL stimulates dendritic and T cells to a pro-inflammatory phenotype [213]. Activated T cells via ox-LDL are essential for plaque rupture [214]. Oxidized-LDL can activate $\mathrm{T}$ cells through the influence dendritic cells and this process is inhibited by atorvastatin and rosuvastatin. In a study by Frostegård et al. it was shown that statins can disrupt $\mathrm{T}$ cell activation by interfering with the regulation of miRNAs in dendritic cells. These investigators showed that atorvastatin inhibits the induction of miRNA let-7c by ox-LDL in dendritic cells. Therefore, let-7c plays a major role in $\mathrm{T}$ cell activation via ox-LDL-stimulated dendritic cells [198]. It has also been reported that miRNA-146a is responsible for creating inflammatory conditions and is known to be dependent on NF-KB [215]. In fact, miRNA-146a exerts a regulatory effect on NF-KB-dependent genes including IRAK1 and TRAF6 by using a negative-feedback loop [215]. The role of miRNA146 in TLR4 modulation and downstream cytokine signaling has been demonstrated in human monocytes [215] and it participates in anti-atherogenic effects independent of the lipidlowering effects of statins. In this regard, it has previously been reported that patients with CVD not only have higher levels of miRNA-146a/b and its target genes (i.e., IRAK1 and TRAF6), but also increased levels of TLR4 in comparison to non-CVD patients [194]. Combination therapy with statins and RAS inhibitors (i.e., either and ARB, or ACEI) also resulted in decreased levels of miRNA-146a/b, IRAK1 mRNA, TRAF6 mRNA, and TLR4 mRNA in the monocytes of CVD patients, which could potentially explain the anti-atherogenic effects of statins [194]. It would appear that the mechanisms of action of statins as it pertains to TLR inhibition and downstream signaling include a reduction or defect in the TLR receptor, modulatory effects on NF-KB transcription factor, influence on adhesion-signaling molecules and proteins (including MYD88), reduction of IRAK1 and TRAF6 by miRNAs, and finally, disruption of $\mathrm{T}$ cell activation via miRNA let-7c in dendritic cells.

\section{Conclusion}

One of the causal risk factors for CVD includes the deposition of cholesterol and LDL on vascular walls and subsequent stimulation of NLRs and TLRs that mediates the production of pro-inflammatory cytokines to stabilize inflammation. Inflammation results in the migration of immune cells to the atherosclerotic site, smooth muscle cell proliferation, and activation of MMPs, which ultimately leads to plaque rupture and obstructive thrombosis. Statins are one of the most effective treatments for slowing and/or halting the development of atherosclerosis. In addition to their lipid-lowering effects, statins exert inhibitory and/or stimulatory effects on the NLRP3 inflammasome and TLRs. The effects of statins on the NLRP3 complex and TLR pathways are related to their chemistry and pharmacokinetics properties, as well as 'danger signals' such as CCs and/or ox-LDL. Lipophilic statins have a greater number of pleiotropic effects on the NLRP3 complex in comparison to hydrophilic statins. In the context of atherosclerosis and, as mentioned above, CCs and ox-LDL act as 'danger signals' and cause a reduction in the NLRP3 inflammasome in the presence of statins, while metabolic and diabetic disorders cause an activation of the NLRP3 inflammasome. On the other hand, statins decrease cholesterol production through inhibition of the mevalonate pathway, as well as protein prenylation. The decrease in cholesterol production and protein prenylation primarily results in suppression of the TLR4/MyD88/NF-KB signaling pathway and a reduction in the formation of the NLRP3 complex. As a result, immune responses are shifted to an anti-inflammatory response.

Furthermore, statins inhibit NF-KB by decreasing the expression of TLRs 2 and 4, reducing the levels of LOX-1 receptors, exerting positive effects on inhibitory miRNAs, reducing protein adaptors, and stabilizing NF-KB inhibitors. This molecular signaling cascade ultimately has the effect of reducing the expression of TLRs and suppressing the activity of NF-KB.

In conclusion, statins are cost-effective drugs, which should have a continued future in the treatment of atherosclerosis due to both their immune-modulating and lipidlowering effects. Inclusion of statin drugs into a pharmacotherapeutic regimen of medications aimed at combatting atherosclerosis [e.g., medications for inhibiting the absorption of intestinal cholesterol (ezetimibe), fibrates to lower serum triglycerides, antiplatelet drugs to prevent the formation of blood clots, newer proprotein convertase subtilisin kexin type 9 (PCSK9) inhibitors, etc.] should increase the pharmacological effectiveness of this approach and improve long-term outcomes in patients with CVD. In our opinion, the addition of statin drugs to an already existing regimen of anti-atherosclerotic medications should pose no problems with current clinical practice guidelines, as this class of lipid-lowering agents is typically already utilized, but should preferably be firmly incorporated into standard practice algorithms for the treatment of atherosclerosis in an effort to fully exploit the additional beneficial immune-modulating effects of statins.

Confirmation of Figure Originality The authors confirm the figures originality and they have not previously been published. All figures were drawn with ChemDraw, Microsoft office PowerPoint and Adobe Photoshop softwares.

Funding information None. 


\section{Compliance with ethical standards}

Conflict of Interest Dr. Banach has served on the speaker's bureau and as an advisory board member for Amgen, Sanofi, Aventis, and Lilly. Dr. Al-Rasadi received research grant from Sanofi, served on the speaker's bureau and as an advisory board member for Sanofi, Astra Zeneca and Pfizer. Other authors have no conflict of interests.

Open Access This article is licensed under a Creative Commons Attribution 4.0 International License, which permits use, sharing, adaptation, distribution and reproduction in any medium or format, as long as you give appropriate credit to the original author(s) and the source, provide a link to the Creative Commons licence, and indicate if changes were made. The images or other third party material in this article are included in the article's Creative Commons licence, unless indicated otherwise in a credit line to the material. If material is not included in the article's Creative Commons licence and your intended use is not permitted by statutory regulation or exceeds the permitted use, you will need to obtain permission directly from the copyright holder. To view a copy of this licence, visit http://creativecommons.org/licenses/by/4.0/.

\section{References}

1. Ference BA, Ginsberg HN, Graham I, Ray KK, Packard CJ, Bruckert E et al (2017) Low-density lipoproteins cause atherosclerotic cardiovascular disease. 1. Evidence from genetic, epidemiologic, and clinical studies. A consensus statement from the European Atherosclerosis Society Consensus Panel. Eur Heart J 38(32):2459-2472

2. Libby P, Ridker PM, Maseri A (2002) Inflammation and atherosclerosis. Circulation 105(9):1135-1143

3. Hansson GK (2005) Inflammation, atherosclerosis, and coronary artery disease. N Engl J Med 352(16):1685-1695

4. Karasawa T, Takahashi M (2017) Role of NLRP3 inflammasomes in atherosclerosis. J Atheroscler Thromb 24(5):443-451

5. Kim YK, Shin J-S, Nahm MH (2016) NOD-like receptors in infection, immunity, and diseases. Yonsei Med J 57(1):5-14

6. Asadzadeh-Aghdaei H, Mashayekhi K, Koushki K, Azimzadeh P, Rostami-Nejad M, Amani D et al (2019) V617F-independent upregulation of JAK2 gene expression in patients with inflammatory bowel disease. J Cell Biochem

7. Lundberg AM, Hansson GK (2010) Innate immune signals in atherosclerosis. Clin Immunol 134(1):5-24

8. Andreakos E, Foxwell B, Feldmann M (2004) Is targeting Tolllike receptors and their signaling pathway a useful therapeutic approach to modulating cytokine-driven inflammation? Immunol Rev 202(1):250-265

9. Cassel SL, Joly S, Sutterwala FS, editors. (2009) The NLRP3 inflammasome: a sensor of immune danger signals. Seminars in immunology. Elsevier

10. Galkina E, Ley K (2009) Immune and inflammatory mechanisms of atherosclerosis. Annu Rev Immunol 27

11. Chen GY, Nuñez G (2010) Sterile inflammation: sensing and reacting to damage. Nat Rev Immunol 10(12):826

12. Woollard KJ, Geissmann F (2010) Monocytes in atherosclerosis: subsets and functions. Nat Rev Cardiol 7(2):77

13. Ross R (1986) The pathogenesis of atherosclerosis - an update. N Engl J Med 314(8):488-500

14. Abela GS (2010) Cholesterol crystals piercing the arterial plaque and intima trigger local and systemic inflammation. J Clin Lipidol 4(3):156-164
15. Chatzizisis YS, Coskun AU, Jonas M, Edelman ER, Feldman CL, Stone PH (2007) Role of endothelial shear stress in the natural history of coronary atherosclerosis and vascular remodeling: molecular, cellular, and vascular behavior. J Am Coll Cardiol 49(25): 2379-2393

16. Zalewski A, Macphee C (2005) Role of lipoprotein-associated phospholipase A2 in atherosclerosis: biology, epidemiology, and possible therapeutic target. Arterioscler Thromb Vasc Biol 25(5): 923-931

17. Libby P, Ridker PM (2006) Inflammation and atherothrombosis: from population biology and bench research to clinical practice. J Am Coll Cardiol 48(9 Supplement):A33-A46

18. Ridker PM (2016) From C-reactive protein to interleukin-6 to interleukin-1: moving upstream to identify novel targets for atheroprotection. Circ Res 118(1):145-156

19. Duewell P, Kono H, Rayner KJ, Sirois CM, Vladimer G, Bauernfeind FG et al (2010) NLRP3 inflammasomes are required for atherogenesis and activated by cholesterol crystals. Nature 464(7293): 1357

20. Xu XH, Shah PK, Faure E, Equils O, Thomas L, Fishbein MC et al (2001) Toll-like receptor-4 is expressed by macrophages in murine and human lipid-rich atherosclerotic plaques and upregulated by oxidized LDL. Circulation 104(25):3103-3108

21. Maleki F, Mashayekhi K, Badiee Kheirabadi SE, Mousavi MJ, Sankian M (2020) A convenient method for solubilization and refolding recombinant proteins: an experience from recombinant mouse TGF- $\beta 1$. Res Mol Med 8(1):0

22. Abdi A, Hosseinpour M, Mashayekhi K, Mousavi MJ, Badiee Kheirabadi SE, Sankian M (2019) Optimization of cloning conditions for high-level production of recombinant mouse interleukin2 in Escherichia coli. Res Mol Med 7(1):16-25

23. Mashayekhi K, Ganji A, Sankian M (2020) Designing a new dimerized anti human TNF- $\alpha$ aptamer with blocking activity. Biotechnol Prog:e2969

24. Garlanda C, Dinarello CA, Mantovani A (2013) The interleukin-1 family: back to the future. Immunity 39(6):1003-1018

25. Dinarello CA (2018) Overview of the IL-1 family in innate inflammation and acquired immunity. Immunol Rev 281(1):8-27

26. Dinarello CA (2005) Blocking IL-1 in systemic inflammation. J Exp Med 201(9):1355-1359

27. Elhage R, Jawien J, Rudling M, Ljunggren H-G, Takeda K, Akira $\mathrm{S}$ et al (2003) Reduced atherosclerosis in interleukin-18 deficient apolipoprotein E-knockout mice. Cardiovasc Res 59(1):234-240

28. Chen C-J, Kono H, Golenbock D, Reed G, Akira S, Rock KL (2007) Identification of a key pathway required for the sterile inflammatory response triggered by dying cells. Nat Med 13(7): 851

29. Dinarello CA (1998) Interleukin-1 $\beta$, Interleukin-18, and the Interleukin-1 $\beta$ Converting Enzyme a. Ann N Y Acad Sci 856(1):1-11

30. Joosten LA, Netea MG, Fantuzzi G, Koenders MI, Helsen MM, Sparrer H et al (2009) Inflammatory arthritis in caspase 1 genedeficient mice: contribution of proteinase 3 to caspase 1independent production of bioactive interleukin- $1 \beta$. Arthritis Rheum 60(12):3651-3662

31. Coeshott C, Ohnemus C, Pilyavskaya A, Ross S, Wieczorek M, Kroona $\mathrm{H}$ et al (1999) Converting enzyme-independent release of tumor necrosis factor $\alpha$ and IL-1 $\beta$ from a stimulated human monocytic cell line in the presence of activated neutrophils or purified proteinase 3. Proc Natl Acad Sci 96(11):6261-6266

32. Dinarello CA (2009) Immunological and inflammatory functions of the interleukin-1 family. Annu Rev Immunol 27:519-550

33. Mizutani H, Schechter N, Lazarus G, Black RA, Kupper TS (1991) Rapid and specific conversion of precursor interleukin 1 beta (IL-1 beta) to an active IL-1 species by human mast cell chymase. J Exp Med 174(4):821-825 
34. Galea J, Armstrong J, Gadsdon P, Holden H, Francis SE, Holt CM (1996) Interleukin-1 beta in coronary arteries of patients with ischemic heart disease. Arterioscler Thromb Vasc Biol 16(8):1000 1006

35. Kirii H, Niwa T, Yamada Y, Wada H, Saito K, Iwakura Y et al (2003) Lack of interleukin-1 $\beta$ decreases the severity of atherosclerosis in ApoE-deficient mice. Arterioscler Thromb Vasc Biol 23(4):656-660

36. Galea J, Armstrong J, Gadsdon P, Holden H, Francis SE, Holt CM (1996) Interleukin-1 $\beta$ in coronary arteries of patients with ischemic heart disease. Arterioscler Thromb Vasc Biol 16(8):1000 1006

37. Apostolakis S, Vogiatzi K, Krambovitis E, Spandidos DA (2008) IL-1 cytokines in cardiovascular disease: diagnostic, prognostic and therapeutic implications. Cardiovasc Hematol Agents Med Chem 6(2):150-158

38. Devlin CM, Kuriakose G, Hirsch E, Tabas I (2002) Genetic alterations of IL-1 receptor antagonist in mice affect plasma cholesterol level and foam cell lesion size. Proc Natl Acad Sci 99(9):6280 6285

39. Libby P, Aikawa M (1998) New insights into plaque stabilisation by lipid lowering. Drugs 56(1):9-13

40. Dewberry R, Holden H, Crossman D, Francis S (2000) Interleukin-1 receptor antagonist expression in human endothelial cells and atherosclerosis. Arterioscler Thromb Vasc Biol 20(11): 2394-2400

41. Satoh M, Tabuchi T, Itoh T, Nakamura M (2014) NLRP3 inflammasome activation in coronary artery disease: Results from prospective and randomized study of treatment with atorvastatin or rosuvastatin. Clin Sci 126(3):233-241

42. Tiret L, Godefroy T, Lubos E, Nicaud V, Tregouet D-A, Barbaux S et al (2005) Genetic analysis of the interleukin-18 system highlights the role of the interleukin-18 gene in cardiovascular disease. Circulation 112(5):643-650

43. Protopsaltis J, Kokkoris S, Korantzopoulos P, Milionis HJ, Karzi E, Anastasopoulou A et al (2009) Prediction of long-term functional outcome in patients with acute ischemic non-embolic stroke. Atherosclerosis 203(1):228-235

44. Bhaskar V, Yin J, Mirza AM, Phan D, Vanegas S, Issafras H et al (2011) Monoclonal antibodies targeting IL-1 beta reduce biomarkers of atherosclerosis in vitro and inhibit atherosclerotic plaque formation in Apolipoprotein E-deficient mice. Atherosclerosis 216(2):313-320

45. Ridker PM, Thuren T, Zalewski A, Libby P (2011) Interleukin-1 $\beta$ inhibition and the prevention of recurrent cardiovascular events: rationale and design of the Canakinumab Anti-inflammatory Thrombosis Outcomes Study (CANTOS). Am Heart J 162(4): 597-605

46. Ridker PM (2013) Closing the loop on inflammation and atherothrombosis: why perform the CIRT and CANTOS trials? Trans Am Clin Climatol Assoc 124:174

47. Hoffman HM, Broderick L (2016) The role of the inflammasome in patients with autoinflammatory diseases. J Allergy Clin Immunol 138(1):3-14

48. Masters SL, Simon A, Aksentijevich I, Kastner DL (2009) Horror autoinflammaticus: the molecular pathophysiology of autoinflammatory disease. Annu Rev Immunol 27:621-668

49. He Y, Zeng MY, Yang D, Motro B, Núñez G (2016) NEK7 is an essential mediator of NLRP3 activation downstream of potassium efflux. Nature 530(7590):354

50. Vandanmagsar B, Youm Y-H, Ravussin A, Galgani JE, Stadler K, Mynatt RL et al (2011) The NLRP3 inflammasome instigates obesity-induced inflammation and insulin resistance. Nat Med 17(2):179

51. Kingsbury SR, Conaghan PG, McDermott MF (2011) The role of the NLRP3 inflammasome in gout. J Inflamm Res 4:39
52. Rajamäki K, Lappalainen J, Öörni K, Välimäki E, Matikainen S, Kovanen PT et al (2010) Cholesterol crystals activate the NLRP3 inflammasome in human macrophages: a novel link between cholesterol metabolism and inflammation. PLoS One 5(7):e11765

53. Luo B, Huang F, Liu Y, Liang Y, Wei Z, Ke H et al (2017) NLRP3 inflammasome as a molecular marker in diabetic cardiomyopathy. Front Physiol 8:519

54. Abela GS, Aziz K, Vedre A, Pathak DR, Talbott JD, DeJong J (2009) Effect of cholesterol crystals on plaques and intima in arteries of patients with acute coronary and cerebrovascular syndromes. Am J Cardiol 103(7):959-968

55. Kunjathoor VV, Febbraio M, Podrez EA, Moore KJ, Andersson L, Koehn S et al (2002) Scavenger receptors class AI/II and CD36 are the principal receptors responsible for the uptake of modified low density lipoprotein leading to lipid loading in macrophages. J Biol Chem

56. Peng K, Liu L, Wei D, Lv Y, Wang G, Xiong W et al (2015) $\mathrm{P} 2 \mathrm{X} 7 \mathrm{R}$ is involved in the progression of atherosclerosis by promoting NLRP3 inflammasome activation. Int J Mol Med 35(5): 1179-1188

57. Peter Stachon $M$, Adrian Heidenreich $M$, Ingo Hilgendorf $M$, Dennis Wolf M, Florian Willecke M, Sunaina von Garlen M, et al P2X7 deficiency blocks lesional inflammasome activity and ameliorates atherosclerosis in mice

58. Stachon P, Heidenreich A, Merz J, Hilgendorf I, Wolf D, Willecke F et al (2017) P2X7 deficiency blocks lesional inflammasome activity and ameliorates atherosclerosis in mice. Circulation. https://doi.org/10.1161/CIRCULATIONAHA.117.027400

59. Altaf A, Qu P, Zhao Y, Wang H, Lou D, Niu N (2015) NLRP3 inflammasome in peripheral blood monocytes of acute coronary syndrome patients and its relationship with statins. Coron Artery Dis 26(5):409-421

60. Hendrikx T, Jeurissen ML, van Gorp PJ, Gijbels MJ, Walenbergh SM, Houben T et al (2015) Bone marrow-specific caspase-1/11 deficiency inhibits atherosclerosis development in Ldlr-/- mice. FEBS J 282(12):2327-2338

61. Menu P, Pellegrin M, Aubert J, Bouzourene K, Tardivel A, Mazzolai L et al (2011) Atherosclerosis in ApoE-deficient mice progresses independently of the NLRP3 inflammasome. Cell Death Dis 2(3):e137

62. Baldrighi M, Mallat Z, Li X (2017) NLRP3 inflammasome pathways in atherosclerosis. Atherosclerosis

63. Zheng F, Xing S, Gong Z, Mu W, Xing Q (2014) Silence of NLRP3 suppresses atherosclerosis and stabilizes plaques in apolipoprotein E-deficient mice. Mediat Inflamm 2014

64. Abreu MT, Arditi M (2004) Innate immunity and toll-like receptors: clinical implications of basic science research. J Pediatr 144(4):421-429

65. Wijnand K, Cheng C, Pasterkamp G, Duckers HJ (2010) Toll like receptor 4 in atherosclerosis and plaque destabilization. Atherosclerosis 209(2):314-320

66. Akira S, Uematsu S, Takeuchi O (2006) Pathogen recognition and innate immunity. Cell. 124(4):783-801

67. Mullick AE, Tobias PS, Curtiss LK (2005) Modulation of atherosclerosis in mice by Toll-like receptor 2. J Clin Invest 115(11): 3149-3156

68. Björkbacka H, Kunjathoor VV, Moore KJ, Koehn S, Ordija CM, Lee MA et al (2004) Reduced atherosclerosis in MyD88-null mice links elevated serum cholesterol levels to activation of innate immunity signaling pathways. Nat Med 10(4):416

69. Malik TH, Cortini A, Carassiti D, Boyle JJ, Haskard DO, Botto M (2010) The alternative pathway is critical for pathogenic complement activation in endotoxin-and diet-induced atherosclerosis in low-density lipoprotein receptor-deficient mice. Circulation 122(19):1948-1956 
70. Kiechl S, Egger G, Mayr M, Wiedermann CJ, Bonora E, Oberhollenzer F et al (2001) Chronic infections and the risk of carotid atherosclerosis: prospective results from a large population study. Circulation 103(8):1064-1070

71. Wiedermann CJ, Kiechl S, Dunzendorfer S, Schratzberger P, Egger G, Oberhollenzer F et al (1999) Association of endotoxemia with carotid atherosclerosis and cardiovascular disease: prospective results from the Bruneck Study. J Am Coll Cardiol 34(7): 1975-1981

72. Ashida K, Miyazaki K, Takayama E, Tsujimoto H, Ayaori M, Yakushiji T et al (2005) Characterization of the expression of TLR2 (toll-like receptor 2) and TLR4 on circulating monocytes in coronary artery disease. J Atheroscler Thromb 12(1):53-60

73. Versteeg D, Hoefer I, Schoneveld A, De Kleijn D, Busser E, Strijder C et al (2008) Monocyte toll-like receptor 2 and 4 responses and expression following percutaneous coronary intervention: association with lesion stenosis and fractional flow reserve. Heart 94(6):770-776

74. Volonte D, Liu Z, Musille PM, Stoppani E, Wakabayashi N, Di Y$P$ et al (2013) Inhibition of nuclear factor-erythroid 2-related factor (Nrf2) by caveolin- 1 promotes stress-induced premature senescence. Mol Biol Cell 24(12):1852-1862

75. Holloway JW, Yang IA, Ye S (2005) Variation in the toll-like receptor 4 gene and susceptibility to myocardial infarction. Pharmacogenet Genomics 15(1):15-21

76. Doherty TM, Fisher EA, Arditi M (2006) TLR signaling and trapped vascular dendritic cells in the development of atherosclerosis. Trends Immunol 27(5):222-227

77. Michelsen KS, Wong MH, Shah PK, Zhang W, Yano J, Doherty TM et al (2004) Lack of Toll-like receptor 4 or myeloid differentiation factor 88 reduces atherosclerosis and alters plaque phenotype in mice deficient in apolipoprotein E. Proc Natl Acad Sci 101(29):10679-10684

78. Vink A, Schoneveld AH, van der Meer JJ, van Middelaar BJ, Sluijter JP, Smeets MB et al (2002) In vivo evidence for a role of toll-like receptor 4 in the development of intimal lesions. Circulation 106(15):1985-1990

79. Shishido T, Nozaki N, Takahashi H, Arimoto T, Niizeki T, Koyama Y et al (2006) Central role of endogenous Toll-like receptor-2 activation in regulating inflammation, reactive oxygen species production, and subsequent neointimal formation after vascular injury. Biochem Biophys Res Commun 345(4):14461453

80. Morange P, Tiret L, Saut N, Luc G, Arveiler D, Ferrieres J et al (2004) TLR4/Asp299Gly, CD14/C-260T, plasma levels of the soluble receptor CD14 and the risk of coronary heart disease: The PRIME Study. Eur J Hum Genet 12(12):1041

81. Yang IA, Holloway JW, Ye S (2003) TLR4 Asp299Gly polymorphism is not associated with coronary artery stenosis. Atherosclerosis 170(1):187-190

82. Arbour NC, Lorenz E, Schutte BC, Zabner J, Kline JN, Jones M et al (2000) TLR4 mutations are associated with endotoxin hyporesponsiveness in humans. Nat Genet 25(2):187

83. Kiechl S, Lorenz E, Reindl M, Wiedermann CJ, Oberhollenzer F, Bonora E et al (2002) Toll-like receptor 4 polymorphisms and atherogenesis. N Engl J Med 347(3):185-192

84. Boekholdt SM, Agema WR, Peters RJ, Zwinderman AH, van der Wall EE, Reitsma PH et al (2003) Variants of toll-like receptor 4 modify the efficacy of statin therapy and the risk of cardiovascular events. Circulation 107(19):2416-2421

85. Labrum R, Bevan S, Sitzer M, Lorenz M, Markus HS (2007) Toll receptor polymorphisms and carotid artery intima-media thickness. Stroke 38(4):1179-1184

86. Hernesniemi JA, Raitakari OT, Kähönen M, Juonala M, HutriKähönen N, Marniemi J et al (2008) Toll-like receptor 4 gene (Asp299Gly) polymorphism associates with carotid artery elasticity: the cardiovascular risk in young Finns study. Atherosclerosis 198(1):152-159

87. Banach M, Aronow WS, Serban C, Sahabkar A, Rysz J, Voroneanu L et al (2015) Lipids, blood pressure and kidney update 2014. Pharmacol Res 95-96:111-125

88. Sahebkar A, Watts GF (2013) New therapies targeting apoB metabolism for high-risk patients with inherited dyslipidaemias: what can the clinician expect? Cardiovasc Drugs Ther 27(6):559-567

89. Brown MS, Goldstein JL (1980) Multivalent feedback regulation of HMG CoA reductase, a control mechanism coordinating isoprenoid synthesis and cell growth. J Lipid Res 21(5):505-517

90. Vaughan CJ, Gotto AM, Basson CT (2000) The evolving role of statins in the management of atherosclerosis. J Am Coll Cardiol 35(1): $1-10$

91. Kostner GM, Gavish D, Leopold B, Bolzano K, Weintraub MS, Breslow JL (1989) HMG CoA reductase inhibitors lower LDL cholesterol without reducing $\mathrm{Lp}$ (a) levels. Circulation 80(5): 1313-1319

92. Chruściel P, Sahebkar A, Rembek-Wieliczko M, Serban MC, Ursoniu S, Mikhailidis DP et al (2016) Impact of statin therapy on plasma adiponectin concentrations: a systematic review and meta-analysis of 43 randomized controlled trial arms. Atherosclerosis 253:194-208

93. Parizadeh SMR, Azarpazhooh MR, Moohebati M, Nematy M, Ghayour-Mobarhan M, Tavallaie S et al (2011) Simvastatin therapy reduces prooxidant-antioxidant balance: results of a placebocontrolled cross-over trial. Lipids 46(4):333-340

94. Sahebkar A, Kotani K, Serban C, Ursoniu S, Mikhailidis DP, Jones SR et al (2015) Statin therapy reduces plasma endothelin1 concentrations: a meta-analysis of 15 randomized controlled trials. Atherosclerosis 241(2):433-442

95. Sahebkar A, Serban C, Mikhailidis DP, Undas A, Lip GYH, Muntner P et al (2015) Association between statin use and plasma d-dimer levels: a systematic review and meta-analysis of randomised controlled trials. Thromb Haemost 114(3):546-557

96. Sahebkar A, Serban C, Ursoniu S, Mikhailidis DP, Undas A, Lip GYH et al (2016) The impact of statin therapy on plasma levels of von Willebrand factor antigen: systematic review and metaanalysis of Randomised placebo-controlled trials. Thromb Haemost 115(3):520-532

97. Bielinska A, Gluszko P (2007) Statins-are they potentially useful in rheumatology? Pol Arch Med Wewn 117(9):420

98. Pitt B, Mancini GJ, Ellis SG, Rosman HS, Park J-S, Mcgovern ME (1995) Pravastatin limitation of atherosclerosis in the coronary arteries (PLAC I): reduction in atherosclerosis progression and clinical events. J Am Coll Cardiol 26(5):1133-1139

99. Packard C, Norrie J, Ford I, Cobbe S, Shepherd J (1997) Influence of pravastatin and plasma lipids on clinical events in the West of Scotland Coronary Prevention Study (WOSCOPS). Atherosclerosis 134(1-2):49

100. Jones PH, Davidson MH, Stein EA, Bays HE, McKenney JM, Miller E et al (2003) Comparison of the efficacy and safety of rosuvastatin versus atorvastatin, simvastatin, and pravastatin across doses (STELLAR* Trial). Am J Cardiol 92(2):152-160

101. Pedersen TR, Faergeman O, Kastelein JJ, Olsson AG, Tikkanen MJ, Holme I et al (2005) High-dose atorvastatin vs usual-dose simvastatin for secondary prevention after myocardial infarction: the IDEAL study: a randomized controlled trial. Jama 294(19): 2437-2445

102. Downs JR, Clearfield M, Weis S, Whitney E, Shapiro DR, Beere PA et al (1998) Primary prevention of acute coronary events with lovastatin in men and women with average cholesterol levels: results of AFCAPS/TexCAPS. Jama 279(20):1615-1622

103. Rader DJ (2003) Therapy to reduce risk of coronary heart disease. Clin Cardiol 26(1):2-8 
104. Vaughan CJ, Murphy MB, Buckley BM (1996) Statins do more than just lower cholesterol. Lancet 348(9034):1079-1082

105. Ross R (1999) Atherosclerosis - an inflammatory disease. N Engl J Med 340(2):115-126

106. Davaro F, Forde SD, Garfield M, Jiang Z, Halmen K, Tamburro ND et al (2014) 3-Hydroxyl-3-methylglutaryl coenzyme A (HMG-CoA) reductase inhibitor (statin)-induced 28-kDa interleukin-1 $\beta$ interferes with mature IL-1 $\beta$ signaling. J Biol Chem 289(23):16214-16222

107. Doo YC, Han SJ, Han SW, Park WJ, Choi SH, Cho GY et al (2005) Effect of preexisting statin use on expression of Creactive protein, adhesion molecules, interleukin-6, and antioxidized low-density lipoprotein antibody in patients with unstable angina undergoing coronary stenting. Clin Cardiol 28(2): $72-76$

108. Vasa M, Fichtlscherer S, Adler K, Aicher A, Martin H, Zeiher AM et al (2001) Increase in circulating endothelial progenitor cells by statin therapy in patients with stable coronary artery disease. Circulation 103(24):2885-2890

109. Arboix A, García-Eroles L, Oliveres M, Targa C, Balcells M, Massons J (2010) Pretreatment with statins improves early outcome in patients with first-ever ischaemic stroke: a pleiotropic effect of statins or a beneficial effect of hypercholesterolemia? BMC Neurol 10(1):47

110. Greenwood J, Steinman L, Zamvil SS (2006) Statin therapy and autoimmune disease: from protein prenylation to immunomodulation. Nat Rev Immunol 6(5):358

111. Schönbeck U, Libby P (2004) Inflammation, immunity, and HMG-CoA reductase inhibitors: statins as antiinflammatory agents? Circulation 109(21_suppl_1):II-18-II-26

112. Rosenson RS, Tangney CC, Casey LC (1999) Inhibition of proinflammatory cytokine production by pravastatin. Lancet 353(9157):983-984

113. Charo IF, Taub R (2011) Anti-inflammatory therapeutics for the treatment of atherosclerosis. Nat Rev Drug Discov 10(5):365

114. Albert MA, Danielson E, Rifai N, Ridker PM, Investigators P (2001) Effect of statin therapy on C-reactive protein levels: the pravastatin inflammation/CRP evaluation (PRINCE): a randomized trial and cohort study. Jama 286(1):64-70

115. Ridker PM, Cannon CP, Morrow D, Rifai N, Rose LM, McCabe $\mathrm{CH}$ et al (2005) C-reactive protein levels and outcomes after statin therapy. N Engl J Med 352(1):20-28

116. Nissen SE, Tuzcu EM, Schoenhagen P, Crowe T, Sasiela WJ, Tsai $\mathrm{J}$ et al (2005) Statin therapy, LDL cholesterol, C-reactive protein, and coronary artery disease. N Engl J Med 352(1):29-38

117. Danesh J, Collins R, Appleby P, Peto R (1998) Association of fibrinogen, C-reactive protein, albumin, or leukocyte count with coronary heart disease: meta-analyses of prospective studies. Jama 279(18):1477-1482

118. Jialal I, Devaraj S (2001) Inflammation and atherosclerosis: the value of the high-sensitivity C-reactive protein assay as a risk marker. Pathol Patterns Rev 116(suppl_1):S108-S15

119. Abdin AA, El-Halim MSA, Hedeya SE, El-Saadany AA (2012) Effect of atorvastatin with or without prednisolone on Freund's adjuvant induced-arthritis in rats. Eur J Pharmacol 676(1-3):34-40

120. Leung BP, Sattar N, Crilly A, Prach M, McCarey DW, Payne H et al (2003) A novel anti-inflammatory role for simvastatin in inflammatory arthritis. J Immunol 170(3):1524-1530

121. Van de Ree M, Huisman M, Princen H, Meinders A, Kluft C, Group D-S (2003) Strong decrease of high sensitivity C-reactive protein with high-dose atorvastatin in patients with type 2 diabetes mellitus. Atherosclerosis 166(1):129-135

122. Yuan C, Zhou L, Cheng J, Zhang J, Teng Y, Huang M et al (2012) Statins as potential therapeutic drug for asthma? Respir Res 13(1): 108
123. Merx MW, Liehn EA, Graf J, van de Sandt A, Schaltenbrand M, Schrader J et al (2005) Statin treatment after onset of sepsis in a murine model improves survival. Circulation 112(1):117-124

124. Kandiah N, Feldman HH (2009) Therapeutic potential of statins in Alzheimer's disease. J Neurol Sci 283(1-2):230-234

125. de Bont N, Netea MG, Rovers C, Smilde T, Demacker PN, van der Meer JW et al (1998) LPS-induced cytokine production and expression of LPS-receptors by peripheral blood mononuclear cells of patients with familial hypercholesterolemia and the effect of HMG-CoA reductase inhibitors. Atherosclerosis 139(1):147-152

126. Moutzouri E, Tellis CC, Rousouli K, Liberopoulos EN, Milionis HJ, Elisaf MS et al (2012) Effect of simvastatin or its combination with ezetimibe on Toll-like receptor expression and lipopolysaccharide-induced cytokine production in monocytes of hypercholesterolemic patients. Atherosclerosis 225(2):381-387

127. Kuijk LM, Mandey SH, Schellens I, Waterham HR, Rijkers GT, Coffer PJ et al (2008) Statin synergizes with LPS to induce IL-1 $\beta$ release by THP-1 cells through activation of caspase-1. Mol Immunol 45(8):2158-2165

128. Massonnet B, Normand S, Moschitz R, Delwail A, Favot L, Garcia M et al (2009) Pharmacological inhibitors of the mevalonate pathway activate pro-IL-1 processing and IL-1 release by human monocytes. Eur Cytokine Netw 20(3):112-120

129. Henriksbo BD, Lau TC, Cavallari JF, Denou E, Chi W, Lally JS et al (2014) Fluvastatin causes NLRP3 inflammasome-mediated adipose insulin resistance. Diabetes 63(11):3742-3747

130. Montero MT, Matilla J, Gómez-Mampaso E, Lasunción MA (2004) Geranylgeraniol regulates negatively caspase-1 autoprocessing: implication in the Th1 response against Mycobacterium tuberculosis. J Immunol 173(8):4936-4944

131. Liao YH, Lin YC, Tsao ST, Lin YC, Yang AJ, Huang CT et al (2013) HMG-CoA reductase inhibitors activate caspase-1 in human monocytes depending on ATP release and P2X7 activation. J Leukoc Biol 93(2):289-299

132. Henriksbo BD, Schertzer JD (2015) Is immunity a mechanism contributing to statin-induced diabetes? Adipocyte 4(4):232-238

133. Thurnher M, Nussbaumer O, Gruenbacher G (2012) Novel aspects of mevalonate pathway inhibitors as antitumor agents. Clin Cancer Res. https://doi.org/10.1158/1078-0432.CCR-12-0489

134. Mitchell P, Marette A (2014) Statin-induced insulin resistance through inflammasome activation: sailing between Scylla and Charybdis. Diabetes 63(11):3569-3571

135. Xu JF, Washko GR, Nakahira K, Hatabu H, Patel AS, Fernandez IE et al (2012) Statins and pulmonary fibrosis the potential role of NLRP3 inflammasome activation. Am J Respir Crit Care Med 185(5):547-556

136. Luo B, Li B, Wang W, Liu X, Liu X, Xia Y et al (2014) Rosuvastatin alleviates diabetic cardiomyopathy by inhibiting NLRP3 inflammasome and MAPK pathways in a type 2 diabetes rat model. Cardiovasc Drugs Ther 28(1):33-43

137. Kong F, Ye B, Lin L, Cai X, Huang W, Huang Z (2016) Atorvastatin suppresses NLRP3 inflammasome activation via TLR4/MyD88/NF- KB signaling in PMA-stimulated THP-1 monocytes. Biomed Pharmacother 82:167-172

138. Dichtl W, Dulak J, Frick M, Alber HF, Schwarzacher SP, Ares MP et al (2003) HMG-CoA reductase inhibitors regulate inflammatory transcription factors in human endothelial and vascular smooth muscle cells. Arterioscler Thromb Vasc Biol 23(1):58-63

139. Ortego M, Bustos C, Hernández-Presa MA, Tunon J, Diaz C, Hernández G et al (1999) Atorvastatin reduces NF-kB activation and chemokine expression in vascular smooth muscle cells and mononuclear cells. Atherosclerosis 147(2):253-261

140. Hernández-Presa MA, Martin-Ventura JL, Ortego M, GómezHernández A, Tuñón J, Hernández-Vargas P et al (2002) Atorvastatin reduces the expression of cyclooxygenase- 2 in a 
rabbit model of atherosclerosis and in cultured vascular smooth muscle cells. Atherosclerosis 160(1):49-58

141. Chandrasekar B, Mummidi S, Mahimainathan L, Patel DN, Bailey SR, Imam SZ et al (2006) Interleukin-18-induced human coronary artery smooth muscle cell migration is dependent on NF-KB-and AP-1-mediated matrix metalloproteinase- 9 expression and is inhibited by atorvastatin. J Biol Chem 281(22):15099-15109

142. Mason RP, Walter MF, Day CA, Jacob RF (2006) Active metabolite of atorvastatin inhibits membrane cholesterol domain formation by an antioxidant mechanism. J Biol Chem 281(14):93379345

143. Montero MT, Hernández O, Suárez Y, Jn M, Ferruelo AJ, Martinez-Botas J et al (2000) Hydroxymethylglutaryl-coenzyme A reductase inhibition stimulates caspase-1 activity and Th1cytokine release in peripheral blood mononuclear cells. Atherosclerosis 153(2):303-313

144. Yamamoto A, Hoshi K, Ichihara K (1998) Fluvastatin, an inhibitor of 3-hydroxy-3-methylglutaryl-CoA reductase, scavenges free radicals and inhibits lipid peroxidation in rat liver microsomes. Eur J Pharmacol 361(1):143-149

145. Guijarro C, Kim Y, Schoonover C, Massy Z, O'donnell M, Kasiske B et al (1996) Lovastatin inhibits lipopolysaccharideinduced NF-k B activation in human mesangial cells. Nephrol Dial Transplant 11(6):990-996

146. Li W, Asagami T, Matsushita H, Lee K-H, Tsao PS (2005) Rosuvastatin attenuates monocyte-endothelial cell interactions and vascular free radical production in hypercholesterolemic mice. J Pharmacol Exp Ther 313(2):557-562

147. Han Q-F, Wu L, Zhou Y-H, Wang L-H, Zhang D-Y, Liu T et al (2015) Simvastatin protects the heart against ischemia reperfusion injury via inhibiting HMGB1 expression through PI3K/Akt signal pathways. Int J Cardiol 201:568-569

148. Boland AJ, Gangadharan N, Kavanagh P, Hemeryck L, Kieran J, Barry M et al (2018) Simvastatin suppresses interleukin I $\beta$ release in human peripheral blood mononuclear cells stimulated with cholesterol crystals. J Cardiovasc Pharmacol Ther 1074248418776261

149. Wang S, Xie X, Lei T, Zhang K, Lai B, Zhang Z, et al (2017) Statins attenuate activation of the NLRP3 inflammasome by oxidized-LDL or TNF- $\alpha$ in vascular endothelial cells through a PXR-dependent mechanism. Molecular pharmacology. mol. 116.108100.

150. Sadeghi MM, Collinge M, Pardi R, Bender JR (2000) Simvastatin modulates cytokine-mediated endothelial cell adhesion molecule induction: involvement of an inhibitory $\mathrm{G}$ protein. J Immunol 165(5):2712-2718

151. Shi X, Xie W-L, Kong W-W, Chen D, Qu P (2015) Expression of the NLRP3 inflammasome in carotid atherosclerosis. J Stroke Cerebrovasc Dis 24(11):2455-2466

152. Paramel Varghese G, Folkersen L, Strawbridge RJ, Halvorsen B, Yndestad A, Ranheim T et al (2016) NLRP 3 inflammasome expression and activation in human atherosclerosis. J Am Heart Assoc 5(5):e003031

153. Bauernfeind FG, Horvath G, Stutz A, Alnemri ES, MacDonald K, Speert D, et al (2009) Cutting edge: NF-KB activating pattern recognition and cytokine receptors license NLRP3 inflammasome activation by regulating NLRP3 expression. The Journal of Immunology. jimmunol. 0901363.

154. Lin Q, Li M, Fang D, Fang J, Su SB (2011) The essential roles of Toll-like receptor signaling pathways in sterile inflammatory diseases. Int Immunopharmacol 11(10):1422-1432

155. Choi S-H, Harkewicz R, Lee JH, Boullier A, Almazan F, Li AC et al (2009) Lipoprotein accumulation in macrophages via toll-like receptor-4-dependent fluid phase uptake. Circ Res 104(12):13551363
156. Michelsen KS, Doherty TM, Shah PK, Arditi M (2004) TLR signaling: an emerging bridge from innate immunity to atherogenesis. J Immunol 173(10):5901-5907

157. Barton GM, Medzhitov R (2003) Toll-like receptor signaling pathways. Science 300(5625):1524-1525

158. Berridge MV, Tan AS, McCoy KD, Wang R (1996) The biochemical and cellular basis of cell proliferation assays that use tetrazolium salts. Biochemica 4(1):14-19

159. Brand K, Page S, Rogler G, Bartsch A, Brandl R, Knuechel R et al (1996) Activated transcription factor nuclear factor-kappa B is present in the atherosclerotic lesion. J Clin Invest 97(7):17151722

160. Morishita R, Sugimoto T, Aoki M, Kida I, Tomita N, Moriguchi A et al (1997) In vivo transfection of cis element "decoy" against nuclear factor- $\mathrm{kB}$ binding site prevents myocardial infarction. Nat Med 3(8):894

161. Peng H-B, Libby P, Liao JK (1995) Induction and stabilization of I $\kappa \mathrm{B} \alpha$ by nitric oxide mediates inhibition of NF- $\kappa \mathrm{B}$. J Biol Chem 270(23):14214-14219

162. Ozbek E, Cekmen M, Ilbey YO, Simsek A, Polat EC, Somay A (2009) Atorvastatin prevents gentamicin-induced renal damage in rats through the inhibition of p38-MAPK and NF-kB pathways. Ren Fail 31(5):382-392

163. Koksal M, Eren MA, Turan MN, Sabuncu T (2011) The effects of atorvastatin and rosuvastatin on oxidative stress in diabetic patients. Eur J Intern Med 22(3):249-253

164. Zhang W, Du Q, Li H, Sun A, Qiu Z, Wu C et al (2012) The therapeutic effect of Rosuvastatin on cardiac remodelling from hypertrophy to fibrosis during the end-stage hypertension in rats. J Cell Mol Med 16(9):2227-2237

165. Zaitone SA, Abo-Gresha NM (2012) Rosuvastatin promotes angiogenesis and reverses isoproterenol-induced acute myocardial infarction in rats: role of iNOS and VEGF. Eur J Pharmacol 691(1-3):134-142

166. Liu X, Li B, Wang W, Zhang C, Zhang M, Zhang Y et al (2012) Effects of HMG-CoA reductase inhibitor on experimental autoimmune myocarditis. Cardiovasc Drugs Ther 26(2):121-130

167. Rajesh M, Bátkai S, Kechrid M, Mukhopadhyay P, Lee W-S, Horváth B et al (2012) Cannabinoid 1 receptor promotes cardiac dysfunction, oxidative stress, inflammation, and fibrosis in diabetic cardiomyopathy. Diabetes 61(3):716-727

168. Ti Y, Xie G-1, Wang Z-h, Bi X-1, Ding W-y, Wang J, et al (2011) TRB3 gene silencing alleviates diabetic cardiomyopathy in a type 2 diabetic rat model. Diabetes. DB 110549.

169. Baraka A, Mikhail M, Guemei A, El Ghotny S (2009) Effect of targeting mitogen-activated protein kinase on cardiac remodeling in rats. J Cardiovasc Pharmacol Ther 14(4):339-346

170. Tian X, Wong W, Xu A, Chen Z, Lu Y, Liu L et al (2011) Rosuvastatin improves endothelial function in $\mathrm{db} / \mathrm{db}$ mice: role of angiotensin II type 1 receptors and oxidative stress. Br J Pharmacol 164(2b):598-606

171. Pirillo A, Norata GD, Catapano AL (2013) LOX-1, OxLDL, and atherosclerosis. Mediat Inflamm 2013

172. Ulrich-Merzenich G, Zeitler H (2013) The lectin-like oxidized low-density lipoprotein receptor-1 as therapeutic target for atherosclerosis, inflammatory conditions and longevity. Expert Opin Ther Targets 17(8):905-919

173. Ding Z, Liu S, Wang X, Dai Y, Khaidakov M, Deng X et al (2014) LOX-1, mtDNA damage, and NLRP3 inflammasome activation in macrophages: implications in atherogenesis. Cardiovasc Res 103(4):619-628

174. Lv Z-H, Phuong TA, Jin S-J, Li X-X, Xu M (2017) Protection by simvastatin on hyperglycemia-induced endothelial dysfunction through inhibiting NLRP3 inflammasomes. Oncotarget 8(53): 91291 
175. Abais JM, Xia M, Zhang Y, Boini KM, Li P-L (2015) Redox regulation of NLRP3 inflammasomes: ROS as trigger or effector? Antioxid Redox Signal 22(13):1111-1129

176. Toldo S, Marchetti C, Mauro AG, Chojnacki J, Mezzaroma E, Carbone $\mathrm{S}$ et al (2016) Inhibition of the NLRP3 inflammasome limits the inflammatory injury following myocardial ischemiareperfusion in the mouse. Int J Cardiol 209:215-220

177. Wallentin L, Becker RC, Budaj A, Cannon CP, Emanuelsson H, Held C et al (2009) Ticagrelor versus clopidogrel in patients with acute coronary syndromes. N Engl J Med 361(11):1045-1057

178. Bonaca MP, Bhatt DL, Cohen M, Steg PG, Storey RF, Jensen EC et al (2015) Long-term use of ticagrelor in patients with prior myocardial infarction. N Engl J Med 372(19):1791-1800

179. Nanhwan MK, Ling S, Kodakandla M, Nylander S, Ye Y, Birnbaum Y (2014) Chronic treatment with ticagrelor limits myocardial infarct size: an adenosine and cyclooxygenase-2-dependent effect. Arterioscler Thromb Vasc Biol 34(9):2078-2085

180. Birnbaum Y, Birnbaum GD, Birnbaum I, Nylander S, Ye Y (2016) Ticagrelor and rosuvastatin have additive cardioprotective effects via adenosine. Cardiovasc Drugs Ther 30(6):539-550

181. Thomas MR, Outteridge SN, Ajjan RA, Phoenix F, Sangha GK, Faulkner RE et al (2015) Platelet P2Y12 inhibitors reduce systemic inflammation and its prothrombotic effects in an experimental human model. Arterioscler Thromb Vasc Biol 35(12):2562-2570

182. Cai W, Fang J, Chen Z, Lin Y, Wu L, Chen L (2010) Rosuvastatin enhances the protective effects of ischemic postconditioning on myocardial ischaemia-reperfusion injury in type 2 diabetic rat. Zhonghua Xin Xue Guan Bing Za Zhi 38(9):814-818

183. Vilahur G, Gutiérrez M, Casani L, Varela L, Capdevila A, PonsLladó G, et al (2016) Protective effects of ticagrelor on myocardial injury after infarction. Circulation. CIRCULATIONAHA. 116.024014

184. Ye Y, Nylander S, Birnbaum Y (2017) Unraveling the interaction of aspirin, ticagrelor, and rosuvastatin on the progression of atherosclerosis and inflammation in diabetic mice. Cardiovasc Drugs Ther 31(5-6):489-500

185. Nelson CP, Erridge C (2019) Are toll-like receptors potential drug targets for atherosclerosis? Evidence from genetic studies to date. Immunogenetics 71(1):1-11

186. Zelvyte I, Dominaitiene R, Crisby M, Janciauskiene S (2002) Modulation of inflammatory mediators and pparyand nfkb expression by pravastatin in response to lipoproteins in human monocytes in vitro. Pharmacol Res 45(2):147-154

187. Neurauter G, Wirleitner B, Laich A, Schennach H, Weiss G, Fuchs D (2003) Atorvastatin suppresses interferon- $\gamma$-induced neopterin formation and tryptophan degradation in human peripheral blood mononuclear cells and in monocytic cell lines. Clin Exp Immunol 131(2):264-267

188. Chansrichavala P, Chantharaksri U, Sritara P, Ngaosuwankul N, Chaiyaroj SC (2010) Atorvastatin affects TLR4 clustering via lipid raft modulation. Int Immunopharmacol 10(8):892-899

189. Shen D-Z, Xin S-L, Chen C, Liu T (2013) Effect of atorvastatin on expression of TLR4 and NF- $\mathrm{KB}$ p65 in atherosclerotic rabbits. Asian Pac J Trop Med 6(6):493-496

190. Yang SS, Li R, Qu X, Fang W, Quan Z (2012) Atorvastatin decreases Toll-like receptor 4 expression and downstream signaling in human monocytic leukemia cells. Cell Immunol 279(1):96-102

191. Methe H, Kim J-O, Kofler S, Nabauer M, Weis M (2005) Statins decrease Toll-like receptor 4 expression and downstream signaling in human CD14+ monocytes. Arterioscler Thromb Vasc Biol 25(7):1439-1445

192. Chansrichavala P, Chantharaksri U, Sritara P, Chaiyaroj SC (2009) Atorvastatin attenuates TLR4-mediated NF-[kappa] B activation in a MyD88-dependent pathway. Asian Pac J Allergy Immunol 27(1):49
193. Yuan X, Deng Y, Guo X, Shang J, Zhu D, Liu H (2014) Atorvastatin attenuates myocardial remodeling induced by chronic intermittent hypoxia in rats: partly involvement of TLR-4/ MYD88 pathway. Biochem Biophys Res Commun 446(1):292297

194. Takahashi Y, Satoh M, Minami Y, Tabuchi T, Itoh T, Nakamura M (2010) Expression of miR-146a/b is associated with the Toll-like receptor 4 signal in coronary artery disease: effect of reninangiotensin system blockade and statins on miRNA-146a/b and Toll-like receptor 4 levels. Clin Sci 119(9):395-405

195. Satoh M, Tabuchi T, Minami Y, Takahashi Y, Itoh T, Nakamura M (2012) Expression of let-7i is associated with toll-like receptor 4 signal in coronary artery disease: effect of statins on let-7i and Toll-like receptor 4 signal. Immunobiology 217(5):533-539

196. Satoh M, Takahashi Y, Tabuchi T, Tamada M, Takahashi K, Itoh T et al (2015) Circulating toll-like receptor 4-responsive microRNA panel in patients with coronary artery disease: results from prospective and randomized study of treatment with reninangiotensin system blockade. Clin Sci 128(8):483-491

197. Niessner A, Steiner S, Speidl WS, Pleiner J, Seidinger D, Maurer $\mathrm{G}$ et al (2006) Simvastatin suppresses endotoxin-induced upregulation of toll-like receptors 4 and 2 in vivo. Atherosclerosis 189(2): 408-413

198. Frostegård J, Zhang Y, Sun J, Yan K, Liu A (2016) Oxidized lowdensity lipoprotein (Ox LDL)-treated dendritic cells promote activation of $\mathrm{T}$ cells in human atherosclerotic plaque and blood, which is repressed by statins: micro RNA let-7c is integral to the effect. J Am Heart Assoc 5(9):e003976

199. Kapelouzou A, Giaglis S, Peroulis M, Katsimpoulas M, Moustardas P, Aravanis CV et al (2017) Overexpression of TollLike Receptors 2, 3, 4, and 8 is correlated to the vascular atherosclerotic process in the hyperlipidemic rabbit model: the effect of statin treatment. J Vasc Res 54(3):156-169

200. Földes G, von Haehling S, Okonko DO, Jankowska EA, PooleWilson PA, Anker SD (2008) Fluvastatin reduces increased blood monocyte toll-like receptor 4 expression in whole blood from patients with chronic heart failure. Int J Cardiol 124(1):80-85

201. Yang J, Zhang X-D, Yang J, Ding J-W, Liu Z-Q, Li S-G et al (2011) The cardioprotective effect of fluvastatin on ischemic injury via down-regulation of toll-like receptor 4. Mol Biol Rep 38(5): 3037-3044

202. Vilahur G, Juan-Babot O, Peña E, Oñate B, Casaní L, Badimon L (2011) Molecular and cellular mechanisms involved in cardiac remodeling after acute myocardial infarction. J Mol Cell Cardiol 50(3):522-533

203. Wang Y, Zhang MX, Meng X, Liu FQ, Yu GS, Zhang $\mathrm{C}$ et al (2011) Atorvastatin suppresses LPS-induced rapid upregulation of Toll-like receptor 4 and its signaling pathway in endothelial cells. Am J Phys Heart Circ Phys 300(5):H1743-H1H52

204. Katsargyris A, Klonaris C, Tsiodras S, Bastounis E, Giannopoulos A, Theocharis S (2011) Statin treatment is associated with reduced toll-like receptor 4 immunohistochemical expression on carotid atherosclerotic plaques: a novel effect of statins. Vascular 19(6): 320-326

205. Frantz S, Kobzik L, Kim Y-D, Fukazawa R, Medzhitov R, Lee RT et al (1999) Toll4 (TLR4) expression in cardiac myocytes in normal and failing myocardium. J Clin Invest 104(3):271-280

206. Birks EJ, Felkin LE, Banner NR, Khaghani A, Barton PJ, Yacoub MH (2004) Increased toll-like receptor 4 in the myocardium of patients requiring left ventricular assist devices. J Heart Lung Transplant 23(2):228-235

207. Frantz S, Kelly RA, Bourcier T (2001) Role of TLR-2 in the activation of nuclear factor $\mathrm{KB}$ by oxidative stress in cardiac myocytes. J Biol Chem 276(7):5197-5203

208. Crisby M, Nordin-Fredriksson G, Shah PK, Yano J, Zhu J, Nilsson J (2001) Pravastatin treatment increases collagen content and 
decreases lipid content, inflammation, metalloproteinases, and cell death in human carotid plaques: implications for plaque stabilization. Circulation 103(7):926-933

209. Branen L, Hovgaard L, Nitulescu M, Bengtsson E, Nilsson J, Jovinge $S$ (2004) Inhibition of tumor necrosis factor- $\alpha$ reduces atherosclerosis in apolipoprotein E knockout mice. Arterioscler Thromb Vasc Biol 24(11):2137-2142

210. Hodgkinson CP, Ye S (2008) Statins inhibit toll-like receptor 4mediated lipopolysaccharide signaling and cytokine expression. Pharmacogenet Genomics 18(9):803-813

211. Gojova A, Brun V, Esposito B, Cottrez F, Gourdy P, Ardouin P et al (2003) Specific abrogation of transforming growth factor- $\beta$ signaling in T cells alters atherosclerotic lesion size and composition in mice. Blood 102(12):4052-4058

212. Liu P, Yu Y-RA, Spencer JA, Johnson AE, Vallanat CT, Fong AM et al (2008) CX3CR1 deficiency impairs dendritic cell accumulation in arterial intima and reduces atherosclerotic burden. Arterioscler Thromb Vasc Biol 28(2):243-250
213. Bobryshev Y, Watanabe T (1997) Ultrastructural evidence for association of vascular dendritic cells with T-lymphocytes and with B-cells in human atherosclerosis. J Submicrosc Cytol Pathol 29(2):209-221

214. Liu A, Ming JY, Fiskesund R, Ninio E, Karabina S-A, Bergmark $\mathrm{C}$ et al (2015) Induction of dendritic cell-mediated T-cell activation by modified but not native low-density lipoprotein in humans and inhibition by Annexin A5: involvement of heat shock proteins. Arterioscler Thromb Vasc Biol 35(1):197-205

215. Taganov KD, Boldin MP, Chang K-J, Baltimore D (2006) NF-kBdependent induction of microRNA miR-146, an inhibitor targeted to signaling proteins of innate immune responses. Proc Natl Acad Sci 103(33):12481-12486

Publisher's Note Springer Nature remains neutral with regard to jurisdictional claims in published maps and institutional affiliations.

\title{
Affiliations
}

\author{
Khadijeh Koushki ${ }^{1}$-Sanaz Keshavarz Shahbaz ${ }^{1} \cdot$ Kazem Mashayekhi $^{1} \cdot$ Mahvash Sadeghi $^{1} \cdot$ Zeinab Deris Zayeri $^{2}$. \\ Mahdieh Yousefi Taba ${ }^{3} \cdot$ Maciej Banach ${ }^{4,5} \cdot$ Khalid Al-Rasadi $^{6,7} \cdot$ Thomas P. Johnston $^{8} \cdot$ Amirhossein Sahebkar $^{9,10,11}$ \\ 1 Department of Immunology, Faculty of medicine, Mashhad \\ University of Medical Sciences, Mashhad, Iran \\ 2 Golestan Hospital Clinical Research Development Unit, Ahvaz \\ Jundishapur University of Medical Sciences, Ahvaz, Iran \\ 3 Mashhad University of Medical Science, Mashhad, Iran \\ 4 Department of Hypertension, WAM University Hospital in Lodz, \\ Medical University of Lodz, Zeromskiego 113, Lodz, Poland \\ 5 Polish Mother's Memorial Hospital Research Institute (PMMHRI), \\ Lodz, Poland \\ 6 Medical Research Centre, Sultan Qaboos University, Muscat, Oman \\ 7 Department of Biochemistry, College of Medicine and Health \\ Sciences, Sultan Qaboos University, Muscat, Oman \\ 8 Division of Pharmacology and Pharmaceutical Sciences, School of \\ Pharmacy, University of Missouri-Kansas City, Kansas City, MO, \\ USA \\ 9 Halal Research Center of IRI, FDA, Tehran, Iran \\ 10 Biotechnology Research Center, Pharmaceutical Technology \\ Institute, Mashhad University of Medical Sciences, Mashhad, Iran \\ 11 Neurogenic Inflammation Research Center, Mashhad University of \\ Medical Sciences, Mashhad, Iran
}

